\title{
Phytohormones as Growth Regulators During Abiotic Stress Tolerance in Plants
}

\author{
Ayman EL Sabagh ${ }^{1,2 *}$, Mohammad Sohidul Islam ${ }^{3}$, Akbar Hossain $^{4}$, \\ Muhammad Aamir lqbal ${ }^{5}$, Muhammad Mubeen ${ }^{6}$, Mirza Waleed ${ }^{6}$, Mariana Reginato ${ }^{7}$, \\ Martin Battaglia ${ }^{8}$, Sharif Ahmed ${ }^{9}$, Abdul Rehman ${ }^{10}$, Muhammad Arif $^{11}$, \\ Habib-Ur-Rehman Athar ${ }^{12}$, Disna Ratnasekera ${ }^{13}$, Subhan Danish ${ }^{14}$, \\ Muhammad Ali Raza ${ }^{15}$, Karthika Rajendran ${ }^{16}$, Muntazir Mushtaq ${ }^{17}$, Milan Skalicky ${ }^{18 \dagger}$, \\ Marian Brestic ${ }^{18,19+}$, Walid Soufan ${ }^{20}$, Shah Fahad ${ }^{21}$, Saurabh Pandey ${ }^{22}$, \\ Muhammad Kamran ${ }^{23}$, Rahul Datta ${ }^{24}$ and Magdi T. Abdelhamid ${ }^{25}$
}

OPEN ACCESS

Edited by:

Marco Landi

University of Pisa, Italy

Reviewed by:

Amit Kumar Mishra,

Mizoram University, India

Om Prakash Narayan,

Tufts University, United States

*Correspondence:

Ayman EL Sabagh

ayman.elsabagh@agr.kfs.edu.eg

tORCID:

Milan Skalicky

orcid.org/0000-0002-4114-6909

Marian Brestic

orcid.org/0000-0003-3470-6100

Specialty section:

This article was submitted to Plant-Soil Interactions,

a section of the journal

Frontiers in Agronomy

Received: 26 August 2021 Accepted: 12 January 2022 Published: 03 March 2022

Citation:

EL Sabagh A, Islam MS, Hossain A, Iqbal MA, Mubeen M, Waleed M, Reginato $M$, Battaglia $M$, Ahmed $S$,

Rehman A, Arif M, Athar H-U-R, Ratnasekera D, Danish S, Raza MA, Rajendran K, Mushtaq M, Skalicky M,

Brestic M, Soufan W, Fahad S,

Pandey S, Kamran M, Datta R and

Abdelhamid MT (2022)

Phytohormones as Growth Regulators

During Abiotic Stress Tolerance in

Plants. Front. Agron. 4:765068.

doi: 10.3389/fagro.2022.765068
${ }^{1}$ Department of Field Crops, Faculty of Agriculture, Siirt University, Siirt, Turkey, ${ }^{2}$ Department of Agronomy, Faculty of Agriculture, Kafrelsheikh University, Kafr El-Shaikh, Egypt, ${ }^{3}$ Department of Agronomy, Hajee Mohammad Danesh and Technology University, Dinajpur, Bangladesh, ${ }^{4}$ Department of Agronomy, Bangladesh Wheat and Maize Research Institute, Dinajpur, Bangladesh, ${ }^{5}$ Department of Agronomy, Faculty of Agriculture, University of Poonch, Rawalakot, Pakistan, ${ }^{6}$ Department of Environmental Sciences, COMSATS University Islamabad, Vehari Campus, Vehari, Pakistan, ${ }^{7}$ Departamento de Ciencias Naturales, Facultad de Ciencias Exactas, Instituto de Investigaciones Agrobiotecnológicas, Consejo Nacional de Investigaciones Científicas y Técnicas, Físico-Químicas y Naturales, Universidad Nacional de Río Cuarto, Río Cuarto, Argentina, ${ }^{8}$ Department of Animal Science, College of Agriculture and Life Sciences, Cornell University, Ithaca, NY, United States, ${ }^{9}$ International Rice Research Institute, Bangladesh Office, Dhaka, Bangladesh, ${ }^{10}$ Department of Agronomy, Faculty of Agriculture and Environment, The Islamia University of Bahawalpur, Bahawalpur, Pakistan, ${ }^{11}$ Department of Agronomy, The University of Agriculture, Peshawar, Pakistan, ${ }^{12}$ Institute of Pure and Applied Biology, Bahauddin Zakariya University, Multan, Pakistan, ${ }^{13}$ Department of Agricultural Biology, Faculty of Agriculture, University of Ruhuna, Matara, Sri Lanka, ${ }^{14}$ Department of Soil Science, Faculty of Agricultural Sciences and Technology, Bahauddin Zakariya University, Multan, Pakistan, ${ }^{15}$ College of Agronomy, Sichuan Agricultural University, Chengdu, China, ${ }^{16}$ VIT School of Agricultural Innovations and Advanced Learning (VAIAL), Vellore Institute of Technology (VIT), Vellore, India, ${ }^{17}$ Division of Germplasm Evaluation, ICAR-National Bureau of Plant Genetic Resources (NBPGR), Pusa Campus, New Delhi, India, ${ }^{18}$ Department of Botany and Plant Physiology, Faculty of Agrobiology, Food and Natural Resources, Czech University of Life Sciences Prague, Prague, Czechia, ${ }^{19}$ Department of Plant Physiology, Slovak University of Agriculture, Nitra, Slovakia, ${ }^{20}$ Plant Production Department, College of Food and Agriculture Sciences, King Saud University, Riyadh, Saudi Arabia, ${ }^{21}$ Department of Agronomy, The University of Haripur, Khyber Pakhtunkhwa, Pakistan, ${ }^{22}$ Department of Agriculture, Guru Nanak Dev University, Amritsar, India, ${ }^{23}$ Key Laboratory of Plant Nutrition and Fertilizer in South Region, Ministry of Agriculture, Institute of Agricultural Resources and Environment, Guangdong Academy of Agricultural Sciences, Guangzhou, China, ${ }^{24}$ Department of Soil Science and Pedology, Mendel University in Brno, Brno, Czechia, ${ }^{25}$ Botany Department, National Research Centre, Dokki, Egypt

Phytohormones (PHs) play crucial role in regulation of various physiological and biochemical processes that govern plant growth and yield under optimal and stress conditions. The interaction of these $\mathrm{PHs}$ is crucial for plant survival under stressful environments as they trigger signaling pathways. Hormonal cross regulation initiate a cascade of reactions which finely tune the physiological processes in plant architecture that help plant to grow under suboptimal growth conditions. Recently, various studies have highlighted the role of PHs such as abscisic acid, salicylic acid, ethylene, and jasmonates in the plant responses toward environmental stresses. The involvement of cytokinins, gibberellins, auxin, and relatively novel PHs such as strigolactones and brassinosteroids in plant growth and development has been documented under normal and stress conditions. The recent identification of the first plant melatonin receptor opened the door to this regulatory molecule being considered a new plant hormone. However, polyamines, which are not considered PHs, have been included in this 
chapter. Various microbes produce and secrete hormones which helped the plants in nutrient uptake such as N, P, and Fe. Exogenous use of such microbes help plants in correcting nutrient deficiency under abiotic stresses. This chapter focused on the recent developments in the knowledge related to $\mathrm{PHs}$ and their involvement in abiotic stresses of anticipation, signaling, cross-talk, and activation of response mechanisms. In view of role of hormones and capability of microbes in producing hormones, we propose the use of hormones and microbes as potential strategy for crop stress management.

Keywords: phytohormones, plant growth regulators, abiotic stress, plant tolerance, biosynthesis

\section{INTRODUCTION}

Environmental changes either due to anthropogenic activities or due to abrupt seasonal changes in weather pose serious challenge of survival to plants. Since plants are sessile organisms, they have to face such environmental adverse conditions. Among various environmental changes, water deficit or drought, water logging, high salinity, low or high temperature, heavy metals, and solar radiation are detrimental for optimum plant growth and development (Raza et al., 2020; Hossain et al., 2021). Thus, leading to decreases in biomass and grain yields at a global scale (Achard et al., 2006; Gururani et al., 2015). In extreme environments, different types of abiotic stresses can co-occur. For example, salt stress is frequently interlinked with drought, which can be exacerbated by extreme temperatures (Ashraf and Foolad, 2007; Aslam et al., 2013; Slama et al., 2015; EL Sabagh A et al., 2019; EL Sabagh et al., 2021). The toxic effects of salt have a detrimental impact on the root expansion and control the ability to uptake both nutrients and water (Lambers, 2003; Awais et al., 2017). Plants have developed efficient sensing, signaling, and response mechanisms to cope with these detrimental stresses. One of the most conspicuous examples of these response mechanisms exerted by plants is represented by the PHs, which can be defined as cellular signal molecules that act as chemical messengers in plants under low concentrations, and have paramount functions in the regulation of the responses that plant show to abiotic stresses (Fleet and Sun, 2005; Davies, 2010; Williams, 2011). The signaling pathways are interconnected

\footnotetext{
Abbreviations: ABA, Abscisic acid; ABF, ABA-responsive factor; APX, Ascorbate peroxidase; ARF, Auxin response factor; AsA, Ascorbate; BRs, Brassinosteroids; CA, Cinnamic acid; CAT, Catalase; CKs, Cytokinins; CS, Chlorophyll synthase; DHA, Dehydroascorbate; DHAR, Dehydroascorbate reductase; ET, Ethylene; GAs, Gibberellins; GR, Glutathione reductase; GSH, Reduced glutathione; GSSG, Oxidized glutathione; $\mathrm{H}_{2} \mathrm{~S}$, Hydrogen sulfide; IAA, Indole-3-acetic acid; IAM, Indole-3-acetamide; IAOx, Indole-3-acetaldoxime; IPA, Indole-3-pyruvic acid; IPT, Isopentenyl transferase gene; IPTs, Isopentenyl transferase; JAME, Jasmonic acid methyl ester; JAs, Jasmonic acids; MDHA(R), Monodehydroascorbate (reductase); MTA, Methylthioadenosine; NADPH, Nicotinamide adenine dinucleotide phosphate; NCED, 9-cisepoxy carotenoid di-oxygenase; NO, Nitric oxide; OPDA, Octadecanoid cis (+) 12 oxophytodienoic acid; Pas, Polyamines; PGPR, plant growth-promoting rhizobacteria; Phot, Phototropin; PHs, Phytohormones; PP2C, Protein phosphatase type-2C; PYL9, Pyrabactin-like receptor 9; RAF1, Rubisco accumulation factor 1; RNS, Reactive nitrogen species; ROS, Reactive oxygen species; SA, Salicylic acid; SAM, S-Adenosyl methionine; SOD, Superoxide dismutase; SL, Strigolactones; SnRK4, Sucrose non-fermenting1-related protein kinase 4; TAM, Tryptamine; TFs, Transcription factors; UFAs, Unsaturated fatty acids; ZEP, Zeaxanthin epoxidase.
}

in a complex network that modulate physiological processes to quickly adapt to environmental stresses.

According to $\mathrm{He}$ et al. (2018), there are five general plant defense-related metabolites against abiotic stresses: the cuticle as the external protection, unsaturated fatty acids (UFAs) as membrane modulator and oxylipin precursor, reactive species scavengers, molecular chaperones (proteins and subcellular structures stabilization), and compatible solutes. These defensive metabolites are coordinated by a complex regulatory network that involves the participation of upstream signaling molecules as stress PHs, reactive oxygen species (ROS), hydrogen sulfide $\left(\mathrm{H}_{2} \mathrm{~S}\right)$, nitric oxide (NO), polyamines (PAs), phytochromes, and calcium, as well as downstream gene regulation factors, particularly transcription factors (TFs) (He et al., 2018). At present, nine types of PHs have been identified (Su et al., 2017), including auxins, the first phytohormone discovered (Darwin and Darwin, 1880), salicylates (SA), ethylene (ET), cytokinins (CKs), gibberellins (GAs), brassinosteroids (BRs), jasmonates (JA), abscisic acid (ABA), and strigolactones (SL), the last PHs to be discovered (Gomez-Roldan et al., 2008). Among these PHs, $\mathrm{ABA}, \mathrm{SA}, \mathrm{ET}$, and JA have been recognized to have a central role in the plant's responses to environmental stresses (Peleg and Blumwald, 2011; Wasternack, 2014). Recently, Yadav et al. (2021) reviewed that phytohormones including ABA, BRs, CK, ET, GA, JA, and SA play crucial role in drought stress tolerance in plants through regulation of cellular functions at molecular levels through cell signaling. The SL and BR constitute a new plant hormone of increasing importance due to their involvement in the response against stresses such as extreme temperature and drought (Brewer et al., 2013; Ha et al., 2014; Nolan et al., 2020). Melatonin, a recently identified plant hormone, is involved in multiple physiological actions, such as growth, rooting, seed germination, photosynthesis, and protection against abiotic and biotic stresses (Maheshwari et al., 2015). Although polyamines are high in concentration and poorly translocated within the plant (conversely to PHs), they are necessary for plant growth under normal or stress conditions (Liu et al., 2007).

The homeostasis of PHs is controlled by regulation of metabolic pathways, transport, and cellular compartmentations (Pieterse et al., 2009; Iqbal, 2015b). Recently, mutants of hormone-biosynthetic pathways are generally used to understand integration of hormonal circuits into molecular processes associated with stress responses. Therefore, deciphering how plants can better tolerate environmental stresses with minimum or no reduction in their productivity is an important challenge 
for researchers. Figure 1 shows an overview of microbial phytohormone-mediated stress tolerance mechanisms in plants (Egamberdieva et al., 2017). This review aims to enhance the knowledge of the effects of abiotic stresses on endogenous PHs concentrations, and their role in plant physiology to elucidate the potential mechanisms of phytohormone-mediated abiotic stress responses in plants. This information can be used in forwardthinking solutions for developing climate smart crop cultivars in our dynamically changing world.

\section{PHYTOHORMONES}

\section{Abscisic Acid}

Abscisic acid was discovered in early 1960s and found that this phytohormone was responsible for breaking seed dormancy (Cornforth et al., 1965). Later on, it has been found that it has potential role in plant development and stress adaptive responses in plants (Guschina et al., 2002; Iqbal, 2015a). For example, $\mathrm{ABA}$ is involved in seed maturation and seed dormancy, and regulation of water in plant body through stomatal opening and closing, and adaptations of a plant to environmental stresses. Under water deficit conditions, ABA is biosynthesized in roots and transported to leaves via xylem thereby increase in concentration in the leaves. This increase of the ABA acts as a signal and start signaling cascade in guard cells to regulate cell turgor of guard cells (Danquah et al., 2013; Awan et al., 2017). In the abiotic stress response, the biosynthesis and redistribution of $\mathrm{ABA}$ cause stomatal closure and reduce transpiration rate, restricting cell growth (Peleg and Blumwald, 2011). ABA is quite famous for its functions in plant-water relations (Arkhipova et al., 2020).

ABA up-regulates hormone-responsive transcription factors, and in ABA signaling phosphatases and kinases play role in mediating fast responses to various abiotic stresses (Dar et al., 2017).

ABA biosynthesis pathway is derived from carotenoids (Nambara and Marion-Poll, 2005). Stress stimuli rapidly trigger ABA biosynthesis from $\beta$-carotene oxidative cleavage using 9-cisepoxy carotenoid di-oxygenase (NCED) enzyme. The zeaxanthin epoxidase produces trans-violaxanthin, which gets converted to a 15-C compound called neoxanthin. After that, conversion of xanthoxin to abscisic aldehyde occurs, and then its oxidation leads to ABA production. The biosynthesis of ABA by the $\beta$ glucosidase homologs from ABA-GE has also been reported as an alternate pathway of ABA synthesis in some plant species exposed to abiotic stresses (Xu et al., 2013; Llanes et al., 2014).

Moreover, ABA not only mediate physiological responses through its own signaling, it also regulate physiological responses through interacting with other PHs in plants exposed to abiotic stresses (He et al., 2018). It is worth mentioning that ABA triggers and mobilizes an array of biochemical defenses such as biosynthesis of proline, antioxidants, ROS detoxifying enzymes, heat shock proteins, and unsaturated fatty acids along with the strengthening of cuticular waxes, which enable plants to ward-off adverse effects of abiotic stress to some extent (Ashraf and Foolad, 2007; Chen et al., 2013; Lee and Suh, 2015; Hoque et al., 2016; Huang et al., 2016; Liu et al., 2018; Yin et al., 2018; Singhal et al., 2021).

\section{Ethylene}

Ethylene is in gaseous form and involved in many vital morphophysiological processes such as triple response in germinating seeds, developing flowers, ripening fruits, and triggering plant responses against environmental stimuli. Besides, ET regulates several stress-related biochemical responses of plants exposed to abiotic stresses such as heat, drought, chilling, salinity, heavy metals, water-logging, flooded, or submerged conditions (Awan et al., 2017). For instance, a close association between high ET level and freezing and cold stress was observed in Arabidopsis (Shi et al., 2012) and Medicago truncatula (Zhao et al., 2014), and regulation of ET homeostasis is crucial for sub optimal temperature stress (chilling and freezing) tolerance. High ET levels are help in salt stress tolerance as in salt tolerant Arabidopsis plants. The ETIO1 (ethylene over producer) act positively in salt stress by maintaining $\mathrm{Na}^{+} / \mathrm{K}^{+}$homeostasis and ROS production (Yang et al., 2017). Moreover, it plays a crucial role in altering plants' response to pathogen attack, external mechanical wounding, UV radiations, and nutrients deficiency. ET biosynthesis and accumulation were reported in many cases in response to damage or mechanical injury (Abeles et al., 1992; Kendrick and Chang, 2008).

The biosynthesis of ET, as shown in Figure 2, has been quantified in various plant tissues, wilting flowers, and ripening fruits in plants exposed to abiotic stresses (Kendrick and Chang, 2008). The underlying mechanism for ET biosynthesis gets initiated with S-Adenosyl methionine (SAM), which is the precursor of ET and is usually synthesized in large concentrations in various crops and fruit trees. An enzyme called 1- aminocyclopropane-1-carboxylic acid (ACC) synthase catalyzes the first chain reaction to convert SAM to ACC, and methylthioadenosine (MTA), which subsequently gets recycled to L-methionine. Owing to this recycling, L-methionine levels remain unchanged even when ethylene biosynthesis is at its peak. Moreover, the ET biosynthesis pathway is affected by ACC synthase enzyme, which is extremely labile and tends to limit biosynthesis rate and rises proportionally as that of ethylene levels in tissues, flowers, and fruits (Maheshwari et al., 2015).

\section{Salicylic Acid}

Among phenolic endogenous growth regulators, salicylic acid is one of the most vital growth regulators and has been characterized in almost all plant species belonging to diversified groups. The SA concentration has been reported to be $1 \mu \mathrm{g} \mathrm{g}^{-1}$ of fresh biomass of rice, barley, and soybean crops. Its role as a regulator of an array of biochemical and physiological processes in plants has been identified. It helps in induction of systemic acquired resistance to various pathogens has been widely studied in plants (Misra and Saxena, 2009). However, in plants subjected to salinity and osmotic stresses, the SA role remained somewhat ambiguous in various plant species depending on the intensity and duration of osmotic stress. Simultaneously, SA exogenous application alleviated the adverse effects of salinity (Horváth et al., 2007).

During the 1960s, SA was synthesized from cinnamic acid (CA) by two biosynthesis pathways. One pathway involves a side chain of CA, which undergoes decarboxylation to produce benzoic acid, which is then subjected to 2-hydroxylation leading 


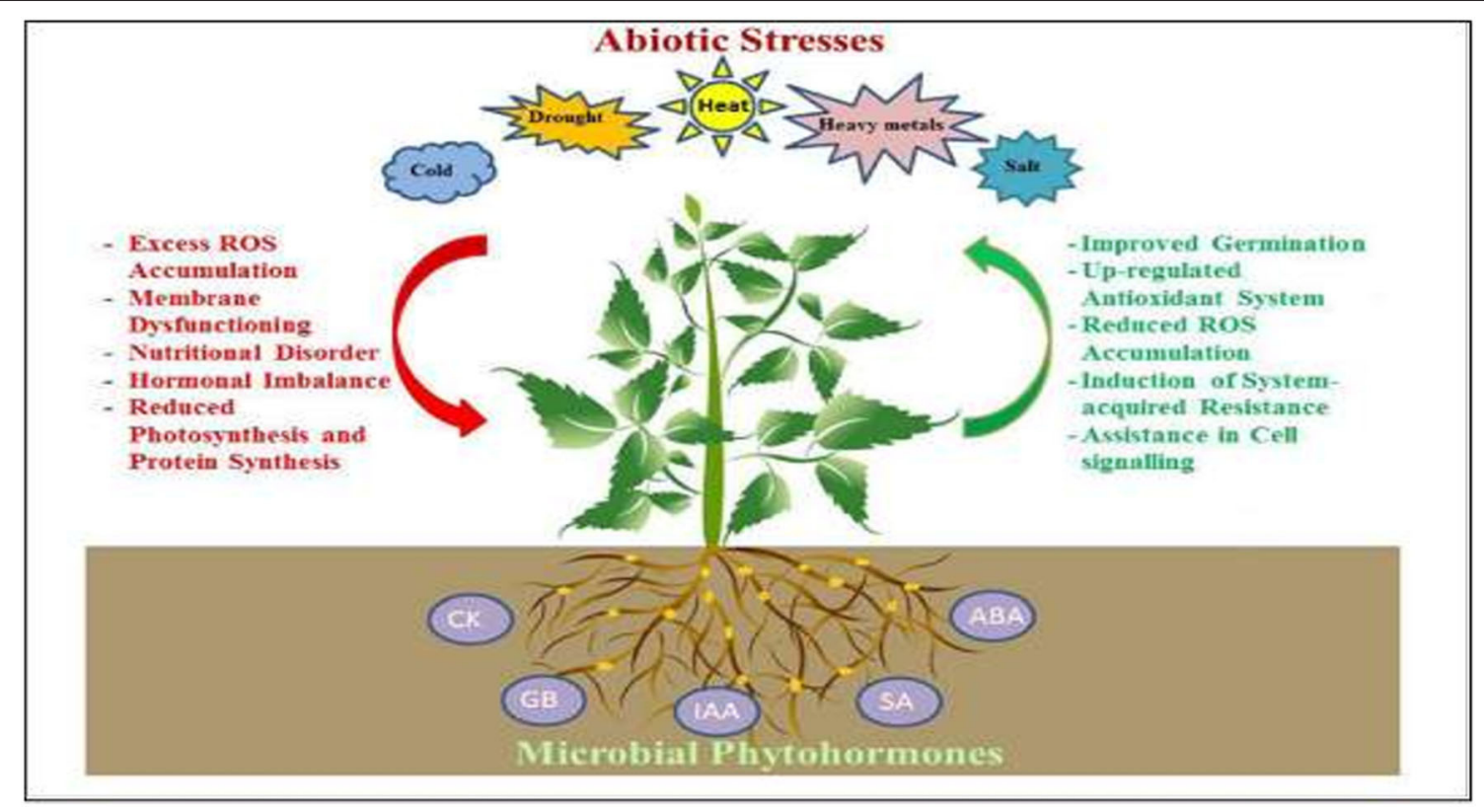

FIGURE 1 | An overview of mechanisms in microbial phytohormone-mediated plant stress tolerance. Several root-associated microbes produce CK, GA, IAA, SA, and $A B A$, which help plants to withstand stress by enhancing their antioxidant potential, by up-regulation of the antioxidant system and by the accumulation of compatible osmolytes thus reducing oxidative stress-induced damage; improving photosynthetic capacity and membrane stability; promoting cell division and stomatal regulation; stimulating the growth of root system, and acquisition of water and nutrients.

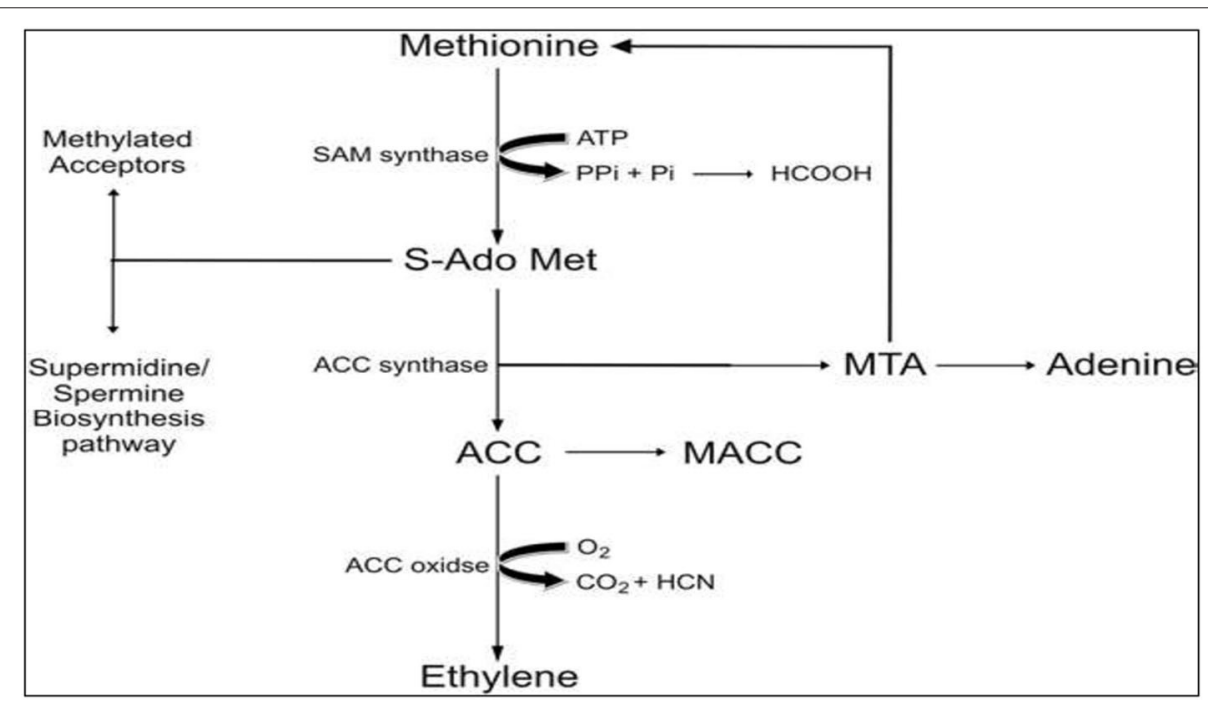

FIGURE 2 | Biosynthesis of ethylene in plant cells.

to the synthesis of SA in crops including tobacco (Yalpani et al., 1993) and rice (Silverman et al., 1995). However, it postulated that some other enzymes involved in this pathway are still unknown. The second pathway of SA biosynthesis involves CA, which gets subjected to 2-hydroxylation, leading to ocoumaric acid production, which is subsequently decarboxylated to biosynthesize SA. Trans-cinnamate-4- hydroxylate enzyme is responsible for catalyzing this reaction (Alibert and Ranjeva,
1971; Alibert et al., 1972). This pathway was firstly studied in seedlings of peas (Russell and Conn, 1967). However, the underlying mechanism of this pathway remains unclear.

\section{Jasmonates}

Jasmonates are a broad group, which are covering various compounds, such as jasmonic acids (JAs), jasmonic acid methyl ester (JAME), precursor of the JAs; octadecanoid cis (+) 12 
oxophytodienoic acid (OPDA), amino acid conjugates, and metabolites such as 12-OH-JA and 11-OH-JA, and often these compounds are involved in plant responses to biotic and abiotic stresses. Jasmonates are found throughout the plant body; however, shoot apex, root tips, immature fruits, and young leaves like tender growing parts show remarkably high concentrations. The synthesizing pathway of JAs is said to be via the octadecanoid pathway, starting at linolenic acid and terminating at (+)-7-epi-JAs (Wasternack, 2007). The major plant organs of biosynthesizing Jasmonates are leaves and roots, while chloroplasts and peroxisomes are the subcellular primary sites of JAs biosynthesis (Cheong and Choi, 2003). Reports showed that development of the embryo and reproductive organs, determination of sex, seed germination and seedling development, root growth, fruit ripening, leaf movements and senescence, gravitropism, the formation of the trichome, and tubers are mediated by JAs (Wasternack and Hause, 2013; Wasternack, 2014). Further, signaling related to defense mechanisms of insects or pathogen are driven wounding is mediated by jasmonates.

JAs have a crucial role in abiotic stress tolerance; thus, studies were focused on these compounds because of their significant protective capacity on plants against stress (Takeuchi et al., 2011). For example, JAs-mediated plant responses are shown against drought stress, ozone stress (Sasaki-Sekimoto et al., 2005), UV-stress, salinity stress, cold stress (Yoshikawa et al., 2007), and temperature stress. In addition, JAs-mediated secondary metabolites production (Chen et al., 2006) is involved in plant movements related to adapt seasonal and circadian rhythms. Wasternack and Hause (2013) reported that jasmonates regulate microbe-associated symbiotic relationships, such as arbuscular mycorrhizal fungi and plant growth-promoting rhizobacteria (PGPR). The jasmonates involved signaling in abiotic stress regulation in Carica papaya (Mahouachi et al., 2007), citrus, and Arabidopsis thaliana (A. thaliana) (Arbona et al., 2010; Brossa et al., 2011) is well-confirmed. Moreover, the involvement of JAs in salt stress signaling in glycophytes such as tomato, barley, and others have been studied. However, the role of jasmonates in halophytic plants' response to salinity stress is yet to be explored. Certain laboratory experiments showed that changes in JAs profiles in response to different abiotic stressors were imposed using $\mathrm{NaCl}$, mannitol/sorbitol, and water stress.

\section{Gibberellins}

The GAs are one of the longest and well-known groups of regulatory hormones integrated into numerous developmental processes of plants such as seed germination, inter-nodal elongation, induced flowering and fruit development (Islam et al., 2021). Recent studies have explored genetic basis and genes encoding GAs biosynthesis and deactivating enzymes using novel biochemical and genetic approaches (Yamaguchi, 2008; Pearce et al., 2015). More than 250 members in the GAs group are reported, though only a few of them are biologically active and play multiple roles in plant development. The cellular level regulation of the GAs is said to be complex. For example, the GAs metabolic pathway phases are regulated by enzymes in small multi-genic families; of those, each member plays a specific pattern of expression. However, two gene families encoding GAs, 20-oxidases (GA20ox) and GA3-oxidases (GA3ox) that catalyze the final steps in the synthesis of bioactive GAs, are strongly associated with GA biosynthesis (Hedden and Thomas, 2012).

Receptor protein of GA is nuclear localized GID1 and binding of GA with receptor protein help to interact with repressor DELLA protein. Protein-protein interacting domain of DELLA protein interact with F-Box protein which recruit SLY1 complex for its ubiquitination via SCF-E3 ligase complex. Upon ubiquitination, DELLA repressor protein is degraded by $26 \mathrm{~S}$ proteasome and thus help in binding of transcription factor with promoter region of GA-inducible genes. Thus, GA mediate signaling by degrading repressor protein that bring about various biochemical and physiological responses. Thus, accumulation of GA in plant tissues either due to endogenous biosynthesis or due to exogenous application counteract negative effects of stresses and thus induce stress tolerance in plants. For instance, under water deficit conditions, decline in endogenous GA level by GA20x6 ectopic expression improved the seed yield and drought stress tolerance in rice (Lo et al., 2017). Moreover, GA regulate redox homeostasis through stimulating electron mobilization in $H$. vulgare (Mark et al., 2016). The involvement of GA in redox equilibrium helps plants to acclimatize in suboptimal growth conditions. GRAS transcription factors play crucial role in plant development and signaling including GA biosynthesis and signal transduction pathways. Liu et al. (2017) demonstrated that abiotic stress treatments like $\mathrm{NaCl}, \mathrm{H}_{2} \mathrm{O}_{2}$, etc. enhanced the GRAS40 expression in tomato. SlGRAS40 interacted with auxin and GA pathways during vegetative and reproductive phases of tomato and transgenic expression of SlGRAS40 plant and its expression induced the drouth and salt tolerance.

\section{Auxins}

Auxins are endogenous plant growth regulators, similar to CKs, and are mainly involved in root/shoot formation and relative growth (Sachs, 2005). Studies have shown that auxins work together with CKs in various cellular or physiological processes such as cell cycle progression, cell expansion, apical dominance, leaf development, and embryonic development during seed maturation (Tromas et al., 2009; Jurado et al., 2010). Indeed, auxins under environmental stresses influence the plant growth responses. In contrast, subsequent alterations in auxin homeostasis due to such environmental changes can result in distorted growth and development in plants, causing altered morphogenesis. Such stress-induced morphogenic responses are an acclimation strategy, which helps prevent or reduce the damaging effects of environmental stresses (Potters et al., 2009; Tognetti et al., 2012).

The genetic studies and in vitro assays claimed that Auxin biosynthetic pathways have one tryptophan (Trp)independent and four Trp-dependent pathways, namely indole3-acetamide (IAM) pathway, indole-3-acetaldoxime (IAOx) pathway, tryptamine (TAM) pathway, and indole-3-pyruvic acid (IPA) pathway (Woodward and Bartel, 2005; Taiz et al., 2015). Amongst them, the TAM and IPA pathways said to be contributed to plant development. 
Similar to GA, receptor protein of auxin is also nuclear localized. Interestingly, receptor protein of auxin is a repressor protein. Binding of auxin with receptor protein or repressor protein recruits $\mathrm{SCF}^{\mathrm{TIR} 1}$-E3 ligase which ubiquitinate repressor protein subsequently degraded by $26 \mathrm{~S}$ proteasome. Degradation of repressor protein allowed to auxin response factors to bind with promoter region of auxin-inducible gene and thus mediate gene expression. Auxin response factor (ARF) family has been identified as transcription factors that mediated auxin's actions; for example, certain ARFs displayed crucial involvements in lateral root development (Wilmoth et al., 2005). A recent study reported that micro RNAs' collective function determined the quantity of lateral root growth, miR390 and TAS3-derived transacting short interfering RNAs and Auxin Responsive Factors forming auxin-responsive regulatory network (Marin et al., 2010). This complex auxin regulatory network has fine-tuned the vigor and elasticity of lateral root growth. However, the involvement of genes that mediate interactive environmental stresses toward growth responses is yet to be discovered.

Variety of abiotic stresses involved in auxin homeostasis, distribution, and their metabolism in the cellular environment. Two molecular mechanisms have been suggested for such alterations in auxin distribution under stress environments; changers in PIN gene expression, which is necessary for polar auxin transport, and inhibitory action of polar auxin transport generated via phenolic compounds accumulated during stress exposure (Kovtun et al., 2000; Potters et al., 2009). Moreover, stress-induced auxin metabolism is regulated by IAA degradation, which is catalyzed by peroxidases (Jain and Khurana, 2009). Thus, auxins can be considered as stress hormones having direct or indirect mediation, modifying the expression of certain stress-responsive genes; among the multifunctions of auxin in plants, the formation of lateral roots considered as of special significance as lateral roots play a key role in plant development regulating the architecture of the root system, stability of the plant and efficient nutrient and water uptake for the whole organism.

\section{Cytokinins}

The CKs are key PHs often considered ABA antagonists and auxin antagonists/synergists in various processes in plants responsible for plant growth, development, and tolerance against different abiotic stresses (Pospíšilová, 2003; Danilova et al., 2016). Besides, other hormonal pathways (e.g., ABA), CKs are activated when a plant is exposed to salt stress. By interacting with other plant hormones like auxins and ABA, CKs can considerably increase salt stress tolerance (Iqbal et al., 2006).

Plant endogenous CKs are adenine derivatives with either isoprenoid or aromatic side chains found in plants at a lower abundance (Sakakibara, 2006). The isoprenoid CKs can be distinguished as isopentenyl adenine (iP), trans-zeatin (tZ), ciszeatin (cZ), or dihydrozeatin-type derivatives according to the hydroxylation and reduction of the side chain. The rate-limiting step of isoprenoid CK biosynthesis is catalyzed by isopentenyl transferase (IPTs). Rivero et al. (2010) generated transgenic tobacco carrying an Agrobacterium tumefaciens isopentenyl transferase gene (IPT). Similarly, the promoter of a senescenceassociated receptor protein kinase $(S A R K)$ gene, from Phaseolus vulgaris, was constructed in front of the IPT gene. These transgenic plants (PSARK::IPT) are more tolerant of droughtinduced leaf senescence, which results in a remarkable level of water stress tolerance. During water stress, a greater reduction in photosynthesis occurs in susceptible plants than the stresstolerant transgenic plants due to the photosynthetic apparatus being degraded in suspectable plants under low photosynthesis conditions. Therefore, CKs may protect photosynthetic processes contributing to the stress tolerance in the transgenic plants (Rivero et al., 2010). In addition, recent studies on CK signaling have suggested that this hormone is indeed involved in plant salt stress responses shown in Figure 1. Synthetic CKs reverse the plants' drought-induced alterations and allow normal growth and developmental activities (Figure 3). Plenty of research findings suggest that CKs support normal growth and development under osmotic stresses and improve plants' drought tolerance ability. However, the precise molecular mechanism of CK-mediated drought tolerance is yet to be discovered.

\section{Melatonin}

In 1995, two groups of researchers simultaneously identified the presence of melatonin ( $\mathrm{N}$-acetyl-5-methox-ytrytamine) in vascular plants for the first time. Melatonin is a pleiotropic molecule with many diverse actions in plants (Wang et al., 2017). It is considered an antioxidant with important actions in the control of ROS (Raza et al., 2020) (Figure 4) and reactive nitrogen species (RNS), among other free radicals, and harmful oxidative molecules present in plant cells. In addition, plant melatonin is involved in multiple physiological actions, such as growth, rooting, seed germination, photosynthesis, and protection against abiotic and biotic stressors (Arnao and Hernández-Ruiz, 2015). The recent identification of the first plant melatonin receptor opened the door to this regulatory molecule being considered a new plant hormone. However, due to the diversity of its actions, melatonin has also been proposed as a plant master regulator.

Melatonin has a range of possible cellular and physiological effects, such as changes in intracellular $\mathrm{Ca}^{2+}$ and the permeability of membranes mediated by ion transporters, changes in the opening and/or closing of stomata carbohydrate, lipid, and nitrogen metabolisms, and also in osmoprotectant metabolites. Melatonin affects processes such as growth promotion, rooting induction, tropism, seed germination promotion, photosynthesis, optimizing efficiency, and leaf water $/ \mathrm{CO}_{2}$ exchange (Sharif et al., 2018). It also regulates other processes, such as ripening or senescence, the internal biological clock, and parthenocarpy. Finally, melatonin also acts as an endogenous plant bio-stimulator against abiotic or biotic stressors (Sun et al., 2014).

One of the basic principles of any animal or plant hormonal function is a receptor responsible for interaction with the hormone and triggering downstream signaling chain elements. One of the most important limitations in studies on melatonin in plants is the lack of an identified receptor. This has also been a hurdle to considering melatonin as a plant hormone. However, 


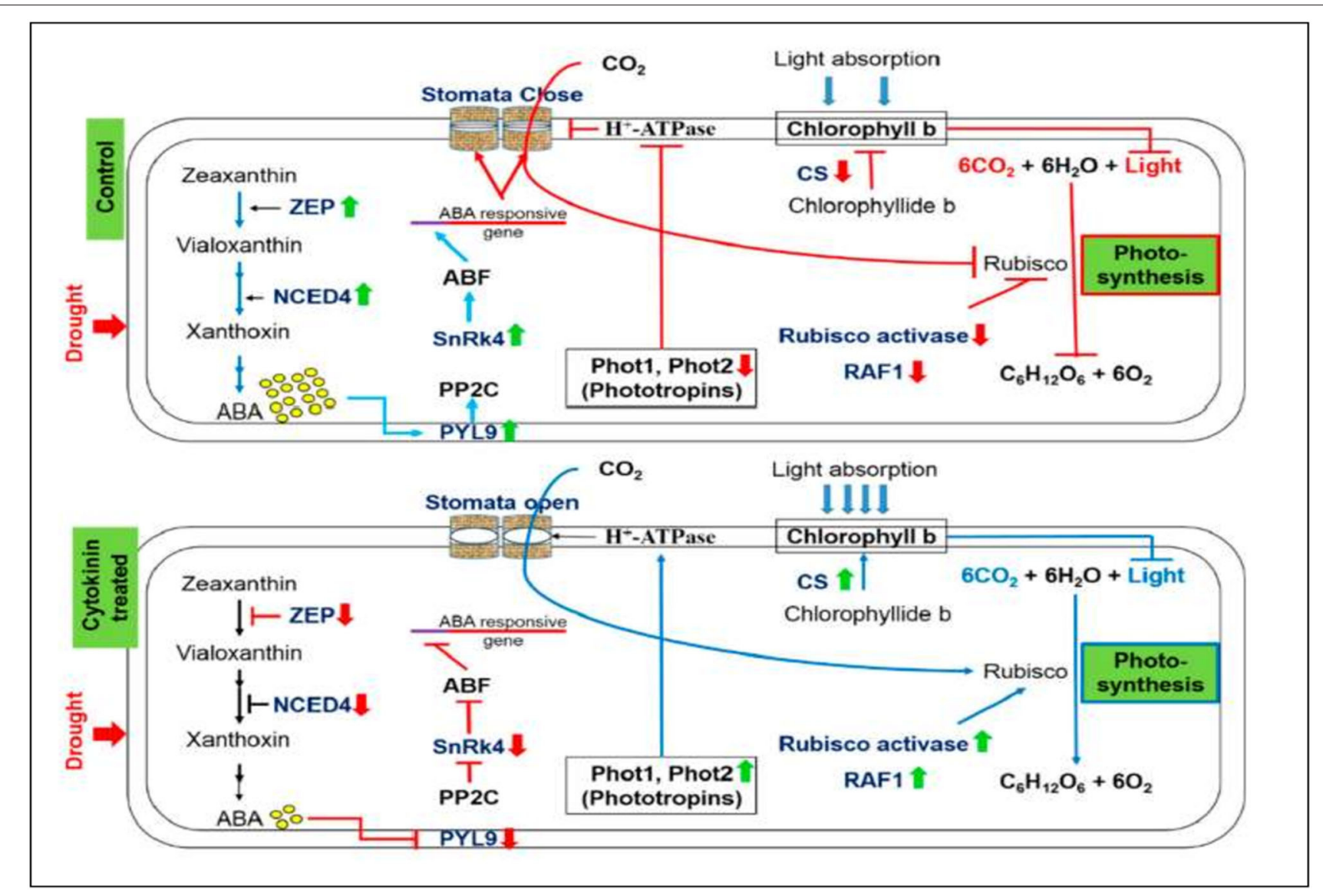

FIGURE 3 | The positive impact of synthetic CK on stomatal conductance, contents of chlorophyll b, and the process of photosynthesis under severe drought stress. Up (green) and down (red) arrows are the symbolic representations of increase and decrease, respectively. ZEP, Zeaxanthin epoxidase; NCED, 9-cis-epoxycarotenoid dioxygenase; ABA, Abscisic acid; PYL9, Pyrabactin-like receptor 9; PP2C, Protein phosphatase type-2C; SnRK4, Sucrose non-fermenting-1-related protein kinase 4; ABF, ABA-responsive factor; Phot, Phototropin; CS, Chlorophyll synthase; RAF1, Rubisco accumulation factor 1 (Gujjar et al., 2020 ).

similar to other plant hormones, identifying the receptor only came after obtaining many biochemical and physiological data relevant to melatonin (Zhang and Chang, 2016). The turning point came with the recent identification of CAND2/PMTR1, a phytomelatonin receptor in A. thaliana. Localized in the plasma membrane with a receptor-like topology, it interacts with the G-protein a subunit (GPA1), while its expression in different tissues is induced by melatonin. Phytomelatoninreceptor binding triggers the dissociation of $\mathrm{Ggb}$ and $\mathrm{Ga}$, which activates NADPH oxidase-dependent $\mathrm{H}_{2} \mathrm{O}_{2}$ production $(\mathrm{RBOH})$, enhancing $\mathrm{Ca}^{2+}$ influx and promoting $\mathrm{K}^{+}$efflux, finally resulting in stomatal closure. Like others, phytomelatonin is a plant hormone that controls stomatal closure through the CAND2/PMTR1-mediated signaling pathway, regulating $\mathrm{H}_{2} \mathrm{O}_{2}$ production. ABA application induced stomatal closure in CAND2 (a melatonin-insensitive phenotype in mutants lacking ATCAND2), suggesting that melatonin-induced stomatal closure has a receptor that is different from that for $\mathrm{ABA}$ while sharing some components with ABA signaling (e.g., Ga subunit, $\mathrm{H}_{2} \mathrm{O}_{2}$, and $\mathrm{Ca}^{2+}$ signals) (Guo et al., 2017; Arnao and Hernández-Ruiz, 2019).

\section{Strigolactones}

Strigolactones (SLs) are carotenoid derived PHs, which exuded from $80 \%$ of the plants that propose a symbiotic relationship with arbuscular soil mycorrhiza (Akiyama and Hayashi, 2006). These PHs were originally discovered as an "ecological signal" for parasitic seed germination and a symbiotic relationship among plants and beneficial microbes. The first natural SL (called strigol) was discovered as a germination stimulant of Striga lutea. This obligate hemiparasite plant requires a living host for germination and initial development, and subsequently, these compounds were collectively termed as strigolactones (Cook et al., 1972).

Several strigolactone analogs, including GR5, GR7, and GR24 (a compound with the highest activity), have been chemically synthesized in many plants, and succeeding characterizations have described their functional roles in various developmental processes, including root development, shoot branching, leaf senescence, reproductive development, and controlling the architecture of plant organs (Gomez-Roldan et al., 2008; Kapulnik et al., 2011; Kohlen et al., 2011; Ruyter-Spira et al., 2011). Like other plant hormones, the major functions of SLs are the development, and its interaction with auxin dominates 


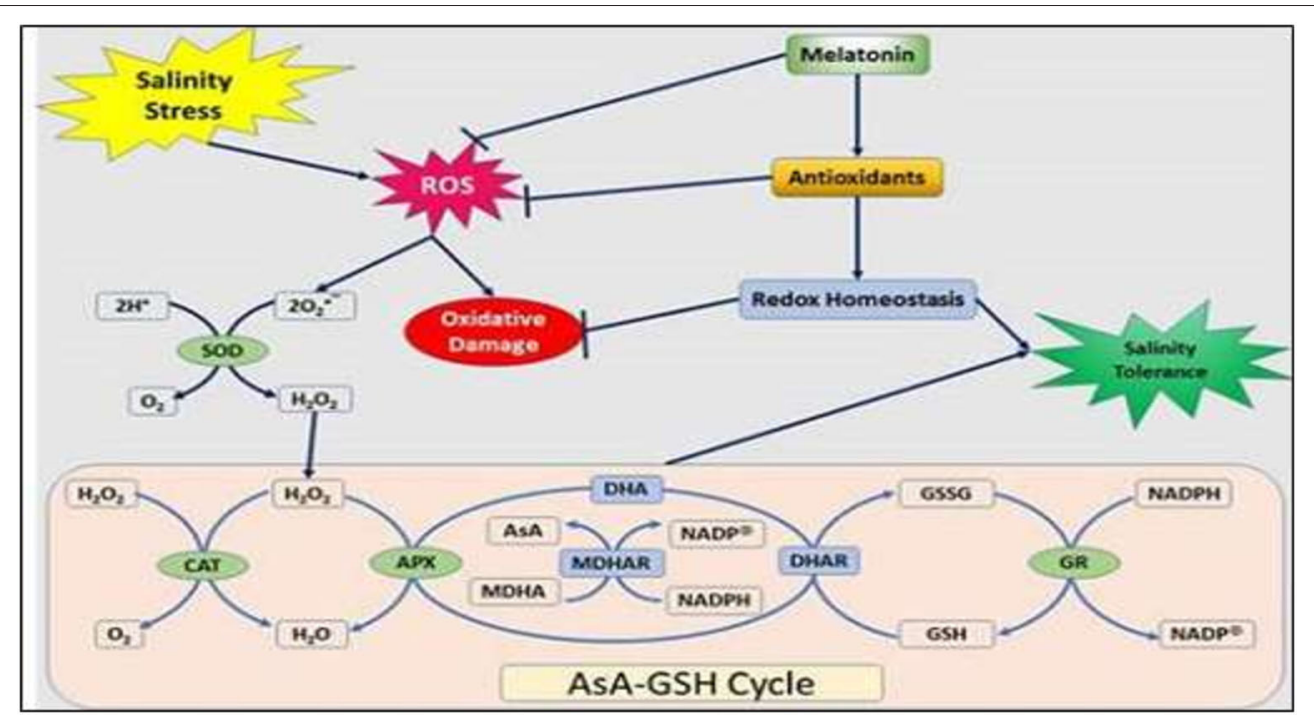

FIGURE 4 | Schematic presentation of the ascorbate-glutathione cycle and a model depicts the melatonin-induced alleviation of NaCl-caused oxidative stress in peanut plants. ROS, reactive oxygen species; SOD, superoxide dismutase; CAT, catalase; APX, ascorbate peroxidase; AsA, ascorbate; MDHA(R), monodehydroascorbate (reductase); NADPH, nicotinamide adenine dinucleotide phosphate, DHA, dehydroascorbate; DHAR, dehydroascorbate reductase; GSH, reduced glutathione; GSSG, oxidized glutathione; and GR, glutathione reductase (EISayed et al., 2020).

in the SL-regulated developmental processes (Hayward et al., 2009). SLs are apocarotenoids derived from carotenoid cleavage mediated by Carotenoid cleavage dioxygenase (CCDs) enzymes (Booker et al., 2005). The first step of biosynthesis occurs in the plastids with the help of three plastids localized enzyme D27, CCD7, and CCD8 utilizing-trans- $\beta$-carotene in plastids producing caprolactone (CL) (Alder et al., 2012). Carlactone is then further oxidized by cytochrome P450 monooxygenase MAX1 or other homologous genes into different forms of SLs by few other unidentified steps catalyzed by novel, unknown enzymes. SLs are involved in the symbiosis relationship of plants and microbes in the rhizosphere. They activate hyphal branching and enhanced the growth and energy metabolism of symbiotic arbuscular mycorrhiza fungi after being exuded from the root.

Furthermore, SLs impact the quantitative development of root nodule symbiosis with symbiotic nitrogen-fixing bacteria (Rochange et al., 2019). The extent of SLs production in plants is strictly regulated and dependent on the stresses that plants confront at various stages of their development. Several studies confirm the importance of SLs in regulating multiple physiological and molecular processes during the adaptation of plants to different abiotic stresses such as salinity, drought, nutrient starvation, temperature, and pathogenic assail (Marzec et al., 2013). Evidence for crosstalk between SLs and other PHs in responses to abiotic stresses suggests that SLs actively participate within regulatory networks of plant stresses.

Recently, Ling et al. (2020) reported that exogenous application of GR24 in seedling of rice resulted in better growth, increased POD and SOD activity, and improved net photosynthetic rate, stomatal conductance, and intercellular $\mathrm{CO}_{2}$ concentrations. These results show that GR24 may alleviate the damage of rice caused by salt stress, improve the adaptability to high-saline environments, and provide a relatively stable yield. The plant produces high amounts of SLs under nutrient deficiency conditions that lead to suppressing shoot branching and stimulating symbiosis (Gomez-Roldan et al., 2008; Umehara et al., 2008). SLs also showed to play a crucial role in nitrogen and phosphorous deficiency, inducing modification of root and shoot architecture and promoting the symbiosis of rhizobial bacteria and AM fungi (Marzec, 2016). As reported above, the significance of SLs has been well-recognized in several stress conditions as salinity, drought, temperature, and nutrient deficiency; however, their establishments as stress-related PHs demand extensive research.

\section{Brassinosteroids}

Brassinosteroids (BRs) are polyhydroxylated steroid PHs. They regulate several physiological and biochemical processes in the plant, such as cell elongation, cell division, photomorphogenesis, xylem differentiation, growth, and reproduction (Nolan et al., 2020). The BRs exist in free and conjugated, and nearly 69 and 5 conjugated and free BRs have been identified (Bajguz, 2011). The BRs are diverse in nature and biological activity. Among the BRs, brassinolide (BL) has been documented as the most active BR, and it was isolated and purified from Brassica napus pollen (Grove et al., 1979). The BRs are closely related to auxins, through the modulation of its transport, coordinating the tropic responses of plant organs ( $\mathrm{Li}$ et al., 2005), and promoting lateral root primordial initiation during lateral root development (Bao et al., 2004). The endoplasmic reticulum most likely served as the site for BRs synthesis. The formation of a protein complex comprising enzymes (metabolon) to efficiently route the substrate to specified enzymes in a single biosynthetic pathway has been anticipated in plants only, and 
BRs biosynthesis occurs through cyto-chromeP450 (CYP), a triterpenoid pathway (Ralston and Yu, 2006; Choe, 2007; Chung et al., 2011). Hydroxylation of membrane-induced campesterol initiates the BR synthetic pathway (Choe et al., 1998). The intermediates gradually become more polar with hydroxyl group addition on side chain on C-22, C-23, and C-2, C-3, C- 6 on steroid rings, respectively (Vukašinović and Russinova, 2018).

Unlike other PHs, BRs are used in contiguity to synthesizing cells rather than long-distance transport. Nevertheless, BRs crosstalk with PHs such as auxin exerts a long-distance effect (Symons et al., 2008; Vriet et al., 2013). The BRs metabolism involves various processes, including acylation, glycosylation, and sulphonation, to maintain the desired levels of bioactive BR in the cells (Saini et al., 2015). The BRs signaling is initiated by leucine rich repeat receptor like kinase (LRR-RLKs) BRI1 which is membrane bound. BRs signaling used two strategies initiation of phosphorylation cascade by kinases and degradation of repressor protein BIN2 and thus allowing transcription factors to bind with DNA binding elements for gene expression. Thus, BRs signal is also amplified during signal transductions. That's why a small amount of BRs is sufficient to initiate developmental programs under normal or stress conditions (Nolan et al., 2017). Numerous studies have documented the abiotic stress tolerance in plants with exogenous application of BRs (Kagale et al., 2007; Bajguz and Hayat, 2009; Yuan et al., 2010; Anjum et al., 2011; Divi et al., 2016). Nevertheless, the BRs need in minimal quantity like other PHs. Therefore, plant responses to exogenous BRs treatment are concentration-dependent. A high $\mathrm{BR}$ application rate is found to inhibit the plant growth, while the opposite is observed at lower concentrations (Chaiwanon and Wang, 2015; Belda-Palazon et al., 2018). The abiotic stresses enhanced ROS generation leading to oxidative stress, while BRs help regulates the cellular ROS level under stressful environments. For instance, 28-homobrassinolide application to Brassica juncea L. plants subjected to combined temperature and salt stress enhanced enzymatic antioxidant activities (SOD, CAT, APOX, DHAR, and MDHAR) and ROS homeostasis (Kaur et al., 2018). Likewise, in Lycopersicum esculentum, BRs application ameliorated the supra optimal temperature-induced photosynthesis inhibition and augmented the carboxylation and activities of the antioxidant system (Ogweno et al., 2007). Recently, Fàbregas et al. (2018) demonstrated that overexpression of BRL3 (vascular BR receptor) promotes drought responses without penalizing growth in Arabidopsis. In another study, Serna et al. (2015) documented the alleviation effects of BRs on lettuce salt-stressed plants. They found that BRs were involved in the partial reversion of $\mathrm{NaCl}$ accumulation in cells. Moreover, some critical agronomic traits in crops are potentially regulated by BRs, such as plant height, leaf angle, and inflorescence structure (Yamamuro et al., 2000; Hong et al., 2003; Sakamoto et al., 2006; Yang et al., 2018). Altogether, these studies demonstrate that BRs are potent $\mathrm{PHs}$ due to their versatile functions, and support the important role of BRs as anti-stress agents. Besides the great progress in the last decade in BRs research, many questions remained unanswered. The complete understanding of the dynamics of BRs homeostasis and its interactions with other PHs will add key knowledge that will allow the modulation of various useful traits in plants and address current challenges in agriculture.

\section{Polyamines}

Polyamines (PAs) are small aliphatic nitrogenous bases produced as a result of cellular metabolism. The PAs have not planted hormones, but due to their involvement in regulating several growth and development processes and responses to abiotic stress in plants, they have been proposed as a new category of plant growth regulators (Liu et al., 2007; Chen et al., 2019). Initially, the ability of PAs to bind with anionic macromolecules was supposed to link with their biological functions, which lead to the consideration of PAs as polycations having distinctive structural roles. However, later may study demonstrated that PAs act as regulatory molecules in key cellular processes such as cell division, cell differentiation, DNA and protein synthesis, and gene expression (Seiler and Raul, 2005; Alcázar et al., 2010; Igarashi and Kashiwagi, 2010; Childs et al., 2017). Furthermore, PAs are involved in various physiological processes in plants including embryogenesis, organogenesis, reproductive development, leaf senescence, and fruit maturity.

Moreover, the several studies have reported the protective role of PAs against environmental stresses (see reviews Alcázar et al., 2010; Gill and Tuteja, 2010; Minocha et al., 2014; Chen et al., 2019). Spermidine (Spd), spermine (Spm), and Putrescine (Put) are the major PAs in plants, while cadaverine (Cad) and diamino propane (Dap) are less studied in plants. The PAs are present in conjugated (covalent and non-covalent bounded) or free form (Gholami et al., 2013). The main product of PAs biosynthetic pathway is Put, which serves as the precursor for Spm and Spd (Xu et al., 2009). In plants, Put biosynthesis occur in three different routes: via Arginine by arginine decarboxylase (ADC) (the most frequent route), via ornithine (Orn) by ornithine decarboxylase (ODC), and citrulline (Cit) by citrulline decarboxylase (CDC) (Chen et al., 2019). The PAs catabolism is contingent on the action of diamine oxidase, and PA oxidase and PAs metabolism is closely associated with several other metabolic pathways in plants. The $\mathrm{H}_{2} \mathrm{O}_{2}$ produced due to PA oxidation is involved in signal transduction and plant responses to biotic and environmental stresses (Freitas et al., 2017; Mellidou et al., 2017; Sariyev et al., 2020). The PA biosynthetic pathway is linked to ethylene synthesis, sharing the same precursor (Sadenosylmethionine) and competing. Further, PAs metabolism is closely associated with nitric oxide generation (Pál et al., 2015), which triggers a signal transduction process related to plant growth. The distribution of PAs is organ and tissue-specific in plants. For instance, Put is the most abundant PA found in leaves, while the higher level of Spd is present in other plant organs (Reginato et al., 2012; Takahashi et al., 2017).

Polyamines are implied in response to different abiotic stresses. Generally, transgenic plants overexpressing PA biosynthetic enzymes, such as spermidine synthase, arginine decarboxylase, and S-adenosylmethionine synthetase, showed the protective roles of polyamines under abiotic stress conditions. Moreover, exogenous application of PAs showed increased stress tolerance in several plant species (Alcázar et al., 2010; Qi et al., 2010; Minocha et al., 2014). 


\section{THE BENEFICIAL EFFECTS OF PGPR-MEDIATED PHYTOHORMONES IN PLANTS UNDER ABIOTIC STRESSES}

Abiotic stresses such as drought, high soil salinity, flooding, heat, cold, oxidative stress, and heavy metals not only deteriorate environmental resources but also reduce crop growth and productivity by reducing nutrient uptake (EL Sabagh et al., 2020b; Javeed et al., 2021). The plant nutrients remarkably influence the physiological and biochemical functions of plants (Raza et al., 2020), and the deficiency of the essential nutrients slows down the growth and development, even go-ahead to the death of plants (Bennett, 1993; Balakrishnan, 1999). Plant breeding and genetic engineering approaches are the best techniques to develop stressresistant plants, but limited success is achieved in this field despite significant efforts.

Increasing nutrient availability and uptake for plants is one way to alleviate nutrient deficiency under abiotic stress conditions. Plant growth-promoting rhizobacteria (PGPR) are the potential candidates to protect plants by colonizing within the rhizosphere and producing antimicrobial metabolites (antagonistic). The PHs produced by such a community of bacteria provide plant health and immunity by regulatory hormones (Maheshwari et al., 2015).

PGPRs associated with plant roots improve plant productivity and immunity through various mechanisms like overproduction of beneficial PHs, consequently increases the root surface area and numbers of root tips, enhances the uptake of nutrients from soils, and reduces the stress-related damages (Kloepper et al., 2004; Çakmakçi, 2016). The PGPR helps fix atmospheric $\mathrm{N}_{2}$ into biologically available $\mathrm{N}$ compounds and produce growth-promoting hormones and prevent the infestation of plant pathogens or increased resistance power of plants against pathogens (Bottini et al., 2004; Compant et al., 2005).

Due to the production and degradation of the major groups of plant hormones, plant growth promotion is facilitated by PGPR via diverse mechanisms. However, plant root exudates have many potential substrates for rhizobacterial growth, including plant hormones or their precursors. Rhizobacterial mediation of plant hormone status shows local effects on root elongation and architecture, mediating water and nutrient capture, and affects plant root-to-shoot hormonal signaling that regulates leaf growth and gas exchange. Combining rhizobacterial traits (or species) influences plant hormones and status, thereby, modifying root architecture (to capture existing soil resources) to make additional resources available (e. g., nitrogen fixation, phosphate solubilization), which may enhance the sustainability of crops (Maheshwari et al., 2015).

In addition to different environmental stresses in crop production and the adverse effects of the chemical fertilizers on the environment, environmentalists push worldwide to reduce chemical fertilizer levels below those recommended for optimum yields. However, such reductions would represent nutrient stress on plants. Hence, the use of PGPR is a great option that facilitates crop productivity with reduced fertilizers. Shaharoona et al. (2008) reported that the use of PGPR strain with $75 \%$ recommended doses of N-P-K fertilizers produced the equivalent yield of wheat (Triticum aestivum L.) that were obtained with the full dose of N-P-K fertilizers (100\%) in the absence of PGPR.

Extracellular plant growth-promoting rhizobacteria (ePGPR) and intracellular plant growth-promoting rhizobacteria (iPGPR) are PGPR classes. The ePGPRs exist within the rhizosphere or in the spaces between the root cortex cells, while the iPGPRs generally exist inside the specialized modular structures of root cells. The bacterial genera under the ePGPR class are Agrobacterium, Arthrobacter, Azotobacter, Azospirillum, Bacillus, Burkholderia, Caulobacter, Chromobacterium, Erwinia, Flavobacterium, Micrococcus, Pseudomonas, and Serratia (Viveros et al., 2010). The iPGPR belongs to the family of Rhizobiaceae that includes species of Allorhizobium, Bradyrhizobium, Mesorhizobium, and Rhizobium (Bhattacharyya and Jha, 2012).

In stress conditions, the growth and development of plants are stimulated by the functions of PGPR. It has been reported by Mantelin and Touraine (2004) that the development of the profuse root in response to PGPR stimulatory effects can directly improve the growth and development of plants. The production of $\mathrm{PHs}$ like IAA, CKs, and GAs under drought, nutrient deficiency, salinity, and metal toxicity stresses changes the root structure (Adesemoye et al., 2008).

Plants uptake more nutrients from the soil due to higher root surface area, contributing to the promotion of plant growth (Vessey, 2003). Moreover, it also increases the nutrients (N, P, and $\mathrm{K}$ ) uptake efficiency of plants due to the PGPR production (Mayak et al., 2004; Turan et al., 2012). PGPB strains improve the $\mathrm{N}_{2}$ fixation and survive plants under stressed soil conditions reported in many previous studies (Gupta et al., 2014; Nadeem et al., 2014).

The PGPR can neutralize or decrease the stress-related hormones (ethylene by bacterial ACC deaminase activity), which are produced in plants under stressed soils, and reduce the inhibitory effects of various pathogens in the forms of biocontrol agents, root colonizers, and environmental protectors, resulting in improve growth and development of plants. PHs produced by PGPR are major signaling molecules employed in the enhancement of crop production. IAA in the majority and other hormones such as ABA, CK, ET, etc. (natural, semi-synthetic, and synthetic) proved beneficial by stabilizing plant immunity, biocontrol, and crop productivity. The role of phytohormone in seed dormancy, seedling emergence, elongation, somatic embryogenesis, initiation, and enhancement brings the immense need to manage increasing food production to account for sustainable agriculture. Phytohormone is exploiting endogenously and exogenously in the maintenance of several physiological traits of plants. It has been revealed that some PGPR secretes novel signaling molecules that also promote plant growth. The use of rhizobacteria signaling in promoting plant growth offers a new window of opportunity, especially to provide novel biological products for enhancing plant growth and development in a sustainable manner (Maheshwari et al., 2015).

Salinity is one of the most significant abiotic stress that hinders crop yield by causing damage to plant growth and development (Abdelhamid et al., 2019; EL Sabagh et al., 2020a). 
Under the saline condition, plants uptake essential nutrients from a diluted source in the presence of highly concentrated nonessential nutrients such as calcium, iron, magnesium, sodium, and chlorine (Fageria et al., 2011; Liu et al., 2020; Monsur et al., 2020). In salt-affected soils, the uptake and use efficiency of nutrients (phosphorus, potassium, and boron) are low due to the negative interactions with higher concentrations of cations and anions. Hence, plants grown in salt-affected soils require a higher amount of nutrients than plants grown in normal soils. Legumes grown in salt-affected soils also adversely affect the biological nitrogen fixation. Jha and Subramanian (2013) reported from a greenhouse study on rice that PGPR inoculated plants under saline conditions increased the uptake of N (26\%), P (16\%), K (31\%), and decreased the uptake of $\mathrm{Na}(71 \%)$ and $\mathrm{Ca}(36 \%)$ resulting exhibited higher germination, survival, dry weight, and plant height as compared to non-inoculated control plants in the same condition.

The PGPR contributed significantly to reduce the nutrient build-up in the soil (Mantelin and Touraine, 2004; Adesemoye et al., 2008). Soil fertility is enhanced due to the levels of nitrogen fixation in legumes. Nitrogen-fixing bacteria metabolize the root exudates and make available nitrogen to synthesize amino acids in plants. The PGPR is the resultant effect of the symbiosis of rhizobia and legume plants. Nitrogen fixation ability depends on the free-living bacteria like Azospirillum, Burkholderia, and Stenotrophomonas (Dobbelaere et al., 2003). Sulfur is an important macronutrient released from sulfate through oxidation of bacteria for the plants (Banerjee and Yesmin, 2002).

For optimum growth and development of plants, phosphorus (P) is an essential macronutrient, although $\mathrm{P}$ is limited to most of the world's soil. Plants uptake P mainly in the form of soluble inorganic phosphate, but $\mathrm{P}$ forms insoluble complexes (unavailable for plant roots) with $\mathrm{Al}$ and $\mathrm{Fe}$, and $\mathrm{Ca}$ and $\mathrm{Mg}$ in acidic and alkaline soils, respectively. A limited amount of bioavailable $\mathrm{P}$ in the soil shows extensive abiotic stress in plants. In this situation, naturally, PGPR microbes present in the soil or artificial inoculation of PGPR strains as a biofertilizer solubilizes the insoluble $\mathrm{P}$, and increases $\mathrm{P}$ availability to plants or helps to develop more lateral roots and root hairs in making more surface area for absorption of inorganic $\mathrm{P}$ and other nutrients (Gyaneshwar et al., 1999). The most efficient phosphate solubilizing bacteria are Rhizobium, Bacillus, and Pseudomonas, and fungi are Aspergillus and Penicillium.

Ehteshami et al. (2007) reported that the phosphatesolubilizing microorganisms could perform positively in promoting plant growth and $\mathrm{P}$ uptake in maize crop under water deficit conditions that lead to the development of improved stress tolerance in plants. The use of PGPB salt-stressed tomato plants increased P uptake (Mayak et al., 2004). The PGPR increased the uptake of $\mathrm{P}$ in peppers under high and low-temperature stress (Martin and Stutz, 2004). Wheat seeds inoculated with Pseudomonas indica and Azotobacter chroococcum increased the uptake of mineral nutrients, especially $\mathrm{Zn}$ (Abadi and Sepehri, 2016). Egamberdiyeva (2007) reported that PGPR inoculation such as Pseudomonas alcaligenes PsA15, Bacillus polymyxa $\mathrm{BcP} 26$, and Mycobacterium phlei MbP18 in maize under nutrient-deficient condition promoted growth and uptake of $\mathrm{N}$, $\mathrm{P}$, and $\mathrm{K}$.

Iron $(\mathrm{Fe})$ toxicity is a severe constraint of rice production in wet conditions. The Bacillus strains can mitigate Fe toxicity symptoms (Asch and Padham, 2005; Terré et al., 2007). PGPR produces siderophores to sequester ferric ions from the soil and supplies them to the plants under iron-limiting stress conditions (Compant et al., 2005). Production of siderophores by PGPR increases nutrient uptake under mineral shortage may, in turn, favor heavy metals sequestration (Khan et al., 2009). Pishchik et al. (2002) reported that barley seeds inoculated with the commercially available PGPR Klebsiella mobilis increased the grain yield by $120 \%$, and decreased two-fold Cd contents in grains when plants are grown in cadmium-contaminated soil. This may be due to free $\mathrm{Cd}$ ions can be bound by bacteria into complex forms that cannot be taken up by the plants. Therefore, inoculation of PGPR can be considered an innovative and costeffective alternative to the availability of nutrients under different abiotic stresses.

\section{CONCLUDING REMARKS}

Abiotic stresses hinder plant growth and development at all phenological stages, particularly at the seed germination and reproductive growth stages. In most of the negative effects in plants caused by abiotic stresses, nutrient deficiency is highly significant. Plants tolerant to abiotic stresses have better ability to preferentially uptake nutrients either due to endogenous hormonal regulation or due to interaction with root zone microbes which release variety of hormones. In view of role of phytohormones in different plant physiological processes, exogenous application of these hormones can improve stress tolerance in plants. In addition, application of hormone producing microbes might have multiple effects in alleviating adverse effects of abiotic stresses on plants. It do not only promote the growth but such application improved the nutrient availability in soil, help in uptake of nutrient and induce stress tolerance in plants. Application of PHs in abiotic stressed-plants is a well-known strategy for crop stress management. The PHs are classified into several classes, and each class has a specific role against specified abiotic stress. Although biosynthetic pathways and signaling pathways of different hormones are known, hormonal cross regulation is poorly understood. Future research needs to explore the molecular mechanisms of different PHs and their cross regulation in alleviating adverse effects of abiotic stresses on plants. In the future, the use of advance biological tools such as genomics, proteomics, transcriptomics, and bioinformatics in this area of research will help in exploring detailed mechanism of abiotic stress tolerance in plants and role of PHs in this regard.

\section{AUTHOR CONTRIBUTIONS}

All authors listed have made a substantial, direct, and intellectual contribution to the work and approved it for publication. 


\section{REFERENCES}

Abadi, V. A. J. M., and Sepehri, M. (2016). Effect of Piriformospora indica and Azotobacter chroococcum on mitigation of zinc deficiency stress in wheat (Triticum aestivum L.). Symbiosis 69, 9-19. doi: 10.1007/s13199-015-0361-z

Abdelhamid, M. T., El-Masry, R. R., Darwish, D. S., Abdalla, M. M., Oba, S., Ragab, R., et al. (2019). "Mechanisms of seed priming involved in salt stress amelioration," in Priming and Pretreatment of Seeds and Seedlings, eds M. Hasanuzzaman, and V. Fotopoulos (Berlin: Springer), 219-251. doi: 10.1007/978-981-13-8625-1_11

Abeles, F. B., Morgan, P. W., and Saltveit, M. E. Jr. (1992). Ethylene in Plant Biology, 2nd Edn. New York, NY: Academic.

Achard, P., Cheng, H., De Grauwe, L., Decat, J., Schoutteten, H., Moritz, T., et al. (2006). Integration of plant responses to environmentally activated phytohormonal signals. Science 311, 91-94. doi: 10.1126/science.1118642

Adesemoye, A. O., Obini, M., and Ugoji, E. O. (2008). Comparison of plant growth-promotion with Pseudomonas aeruginosa and Bacillus subtilis in three vegetables. Braz. J. Microbiol. 39, 423-426. doi: $10.1590 /$ S1517-83822008000300003

Akiyama, K., and Hayashi, H. (2006). Strigolactones: chemical signals for fungal symbionts and parasitic weeds in plant roots. Ann. Bot. 97, 925-931. doi: $10.1093 / \mathrm{aob} / \mathrm{mcl} 063$

Alcázar, R., Altabella, T., Marco, F., Bortolotti, C., Reymond, M., Koncz, C., et al. (2010). Polyamines: molecules with regulatory functions in plant abiotic stress tolerance. Planta 231, 1237-1249. doi: 10.1007/s00425-010-1130-0

Alder, A., Jamil, M., Marzorati, M., Bruno, M., Vermathen, M., Bigler, P., et al. (2012). The path from $\beta$-carotene to carlactone, a strigolactonelike plant hormone. Science 335, 1348-1351. doi: 10.1126/science. 1218094

Alibert, G., and Ranjeva, R. (1971). Recherches sur catalysant la biosynthese des acides phenoliques Chezquercus pedunculata (Ehrh): I. Formation des premiers termes des series cinnamique et benzoique. FEBS Lett. 19, 11-14. doi: 10.1016/0014-5793(71)80593-8

Alibert, G., Ranjeva, R., and Boudet, A. (1972). II. Localisation intracellulaire de la phenylalanine ammoniaque-lyase, de la cinnamate 4-hydroxylase, et de la benzoate synthase. Biochim. Biophys. Acta 279, 282-289. doi: 10.1016/0304-4165(72)90144-4

Anjum, S. A., Wang, L. C., Farooq, M., Hussain, M., Xue, L. L., and Zou, C. M. (2011). Brassinolide application improves the drought tolerance in maize through modulation of enzymatic antioxidants and leaf gas exchange. J. Agron. Crop. Sci. 197, 177-185. doi: 10.1111/j.1439-037X.2010.00459.x

Arbona, V., Argamasilla, R., and Gomez-Cadenas, A. (2010). Common and divergent physiological, hormonal and metabolic responses of Arabidopsis thaliana and Thellungiella halophilato water and salt stress. J. Plant Physiol. 167, 1342-1135. doi: 10.1016/j.jplph.2010.05.012

Arkhipova, T., Martynenko, E., Sharipova, G., Kuzmina, L., Ivanov, I., Garipova, M., et al. (2020). Effects of plant growth promoting rhizobacteria on the content of abscisic acid and salt resistance of wheat plants. Plants 9, 1429. doi: 10.3390/plants9111429

Arnao, M. B., and Hernández-Ruiz, J. (2015). "Melatonin: synthesis from tryptophan and its role in higher plants," in Amino Acids in Higher Plants, ed J.P. F. D'Mello (Boston, MA: CAB International), 390-435. doi: $10.1079 / 9781780642635.0390$

Arnao, M. B., and Hernández-Ruiz, J. (2019). Melatonin and reactive oxygen and nitrogen species: a model for the plant redox network. Melatonin. Res. 2, 152-168. doi: 10.32794/11250036

Asch, F., and Padham, J. L. (2005). "Root associated bacteria suppress symptoms of iron toxicity in lowland rice," in The Global Food \& Product Chain - Dynamics, Innovations, Conflicts, Strategies, eds E. Tielkes, C. Hülsebusch, I. Häuser, A. Deininger, and K. Becker (Stuttgart: MDD GmbH), 276.

Ashraf, M., and Foolad, M. R. (2007). Roles of glycine betaine and proline in improving plant abiotic stress resistance. Environ. Exp. Bot. 59, 206-216. doi: 10.1016/j.envexpbot.2005.12.006

Aslam, M., Zamir, M. S. I., Afzal, I., Yaseen, M., Mubeen, M., and Shoaib, A. (2013). Drought stress, its effect on maize production and development of drought tolerance through potassium application. Agron. Res. Moldavia XLVI, 99-114.

Awais, M., Mubeen, M., Ahmad, A., Habib-ur-Rahman, M., Raza, M. A. S., Ahmad, A., et al. (2017). Nitrogen and plant population change radiation capture and utilization capacity of sunflower in semi-arid environment. Environ. Sci. Pollut. Res. 24, 17511-17525. doi: 10.1007/s11356-017-9308-7

Awan, F. K., Khurshid, M. Y., and Mehmood, A. J. I. J. I. R. B. (2017). Plant growth regulators and their role in abiotic stress management. Int. J. Innov. Res. Biosci. $1,9-21$.

Bajguz, A. (2011). Brassinosteroids: A Class of Plant Hormone, eds S. Hayat, and A. Ahmad, Dordrecht: Springer, 1-27. doi: 10.1007/978-94-007-0189-2_1

Bajguz, A., and Hayat, S. (2009). Effects of brassinosteroids on the plant responses to environmental stresses. Plant Physiol. Biochem. 47, 1-8. doi: 10.1016/j.plaphy.2008.10.002

Balakrishnan, K. (1999). Studies on nutrients deficiency symptoms in chilli (Capsicim annum L.). Indian J. Plant Physiol. 4, 229-231.

Banerjee, M., and Yesmin, L. (2002). "Sulfur-oxidizing plant growth promoting Rhizobacteria for enhanced canola performance," in US Patent Use Systems: Sustainable and Organic Approaches to Meet Human Needs, ed E. Tielkes (Witzenhausen: Tropentag), 446.

Bao, L., Locovei, S., and Dahl, G. P. (2004). Annexin membrane channels are mechanosensitive conduits for ATP. FEBS Lett. 572, 65-68. doi: 10.1016/j.febslet.2004.07.009

Belda-Palazon, B., Gonzalez-Garcia, M. P., Lozano-Juste, J., Coego, A., Antoni, R., Julian, J., et al. (2018). PYL8 mediates ABA perception in the root through noncell-autonomous and ligand-stabilization-based mechanisms. Proc. Natl. Acad. Sci. U.S.A. 115, E11857-E11863. doi: 10.1073/pnas. 1815410115

Bennett, J. M. (1993). "Cultural marginality: identity issues in intercultural training," in Education for the Intercultural Experience (2nd ed.), ed R. M. Paige (Yarmouth, ME: Intercultural Press), 109-135.

Bhattacharyya, P. N., and Jha, D. K. (2012). Plant growth-promoting rhizobacteria (PGPR): emergence in agriculture. World J. Microbiol. Biotechnol. 28, 1327-1350. doi: 10.1007/s11274-011-0979-9

Booker, J., Sieberer, T., Wright, W., Williamson, L., Willett, B., Stirnberg, P., et al. (2005). MAX1 encodes a cytochrome P450 family member that acts downstream of MAX3/4 to produce a carotenoid-derived branch-inhibiting hormone. Dev. Cell 8, 443-449. doi: 10.1016/j.devcel.2005.01.009

Bottini, R., Cassan, F., and Piccoli, P. (2004). Gibberellin production by bacteria and its involvement in plant growth promotion and yield increase. Appl. Microbiol. Biotechnol. 65, 497-503. doi: 10.1007/s00253-004-1696-1

Brewer, P. B., Koltai, H., and Beveridge, C. A. (2013). Diverse roles of strigolactones in plant development. Mol. Plant 6, 18-28. doi: 10.1093/mp/sss 130

Brossa, R., López-Carbonell, M., Jubany-Mar,í T., and Alegre, L. (2011). Interplay between abscisic acid and jasmonic acid and its role in water-oxidative stress in wild-type, ABA-deficient, JA-deficient, and ascorbate-deficient Arabidopsis plants. J. Plant Growth Regul. 30, 322-333. doi: 10.1007/s00344-011-9194-z

Çakmakçi R (2016). Screening of multi-traits rhizobacteria for improving the growth, enzyme activities and nutrient uptake of tea (Camellia sinensis). Commun. Soil Sci. Plant Anal. 47, 13-14. doi: 10.1080/00103624.2016.1206559

Chaiwanon, J., and Wang, Z.-Y. (2015). Spatiotemporal brassinosteroid signaling and antagonism with auxin pattern stem cell dynamics in arabidopsis roots. Curr. Biol. 25, 1031-1042. doi: 10.1016/j.cub.2015.02.046

Chen, D., Shao, Q., Yin, L., Younis, A., and Zheng, B. (2019). Polyamine function in plants: development, and roles in abiotic stress responses. Front. Plant Sci. 9 , 1945. doi: 10.3389/fpls.2018.01945

Chen, H., Chen, X., and Zheng, Y. (2013). The nuclear lamina regulates germline stem cell niche organization via modulation of EGFR signaling. Cell Stem Cell 13, 73-86. doi: 10.1016/j.stem.2013.05.003

Chen, Y.-H., Aires, F., Francis, J. A., and Miller, J. R. (2006). Observed relationships between Arctic longwave cloud forcing and cloud parameters using a neural network. J. Climate 19, 4087-4104. doi: 10.1175/JCLI3839.1

Cheong, J. J., and Choi, Y. D. (2003). Methyl jasmonate as a vital substance. Trends Genet. 19, 409-413. doi: 10.1016/S0168-9525(03)00138-0

Childs, C., Holdsworth, R. E., Christopher, A.-L., Jackson, M.anzocchi T., Walsh, J. J., and Yielding, G. (2017). Introduction to the geometry and growth of normal faults. Geol. Soc. 439, 1-9. doi: 10.1144/SP 439.24

Choe, S. (2007). "Brassinosteroid biosynthesis and metabolism," in Plant Hormones: Biosynthesis, Signal Transduction, Action, ed P. J. Davies (Dordrecht: Kluwer Academic Publishers), 156-178. doi: 10.1007/978-1-4020-2686-7_8

Choe, S., Dilkes, B. P., Fujioka, S., Takatsuto, S., Sakurai, A., and Feldmann, K. A. (1998). The DWF4 gene of Arabidopsis encodes a cytochrome P450 mediates 
multiple 22a ${ }^{*}$-hydroxylation steps in brassinosteroid biosynthesis. Plant Cell 10, 231-243. doi: 10.1105/tpc.10.2.231

Chung, K. Y., Rasmussen, S. G., Liu, T., Li, S., DeVree, B. T., Chae, P. S., et al. (2011). Conformational changes in the $G$ protein $G$ s induced by the $\beta 2$ adrenergic receptor. Nature 477, 611-615. doi: 10.1038/nature10488

Compant, S., Duffy, B., Nowak, J., and Cle ment, C. (2005). Use of plant growthpromoting bacteriafor biocontrol of plant diseases: principles, mechanisms of action, and future prospects. Appl. Environ. Microbiol. 71, 4951-4959. doi: 10.1128/AEM.71.9.4951-4959.2005

Cook, C. E., Whichard, L. P., Wall, M. E., Egley, G. H., Coggon, P., Luhan, P. A., et al. (1972). Germination stimulants. II. The structure of strigol-a potent seed germination stimulant for witchweed (Striga lutea Lour.). J. Amer. Chem. Soc. 94, 6198-6199. doi: 10.1021/ja00772a048

Cornforth, J. W., Milborow, B. V., Ryback, G., and Wareing, P. F. (1965). Identity of sycamore 'dormin' with abscisin II. Nature 205, 1269-1270. doi: $10.1038 / 2051269 b 0$

Danilova, M. N., Kudryakova, N. V., Doroshenko, A. S., Zabrodin, D. A., Vinogradov, N. S., and Kuznetsov, V. V. (2016). Molecular and physiological responses of Arabidopsis thaliana plants deficient in the genes responsible for ABA and cytokinin reception and metabolism to heat shock. Russ. J. Plant Physiol. 63, 308-318. doi: 10.1134/S1021443716030043

Danquah, A., Colcombet, J., and Hirt, H. (2013). The role of ABA and MAPK signaling pathways in plant abiotic stress responses. Biotechnol. Adv. 32, 6. doi: 10.1016/j.biotechadv.2013.09.006

Dar, N. A., Amin, I., Wani, W., Wani, S. A., Shikari, A. B., Wani, S. H., et al. (2017). Abscisic acid: a key regulator of abiotic stress tolerance in plants. Plant Gene 11, 106-111. doi: 10.1016/j.plgene.2017.07.003

Darwin, C., and Darwin, F. (1880). The Power of Movement in Plants. London: John Murray. doi: 10.5962/bhl.title.102319

Davies, P. J. (2010). "The plant hormones: their nature, occurrence, and functions," in ed Plant Hormones, P. J. Davies (Dordrecht: Springer). p. 1-15. doi: 10.1007/978-1-4020-2686-7

Divi, U. K., Rahman, T., and Krishna, P. (2016). Gene expression and functional analyses in brassinosteroid-mediated stress tolerance. Plant Biotechnol. J. 14, 419-432. doi: 10.1111/pbi.12396

Dobbelaere, S., Vanderleyden, J., and Okon, Y. (2003). Plant growth promoting effects of diazotrophs in the rhizosphere. CRC Crit. Rev. Plant Sci. 22, 107-149. doi: 10.1080/713610853

Egamberdieva, D., Davranov, K., Wirth, S., Hashem, A., Abd_Allah, E. F. (2017). Impact of soil salinity on the plant-growth-promoting and biological control abilities of root associated bacteria. Saudi J. Biol. Sci. 24, 1601-1608. doi: 10.1016/j.sjbs.2017.07.004

Egamberdiyeva, D. (2007). The effect of plant growth promoting bacteria on growth and nutrient uptake of maize in two different soils. Appl. Soil Ecol. 36, 184-189. doi: 10.1016/j.apsoil.2007.02.005

Ehteshami, S. M. R., Aghaalikhani, M., Khavazi, K., and Chaichi, M. R. (2007). Effect of phosphate solubilizing microorganisms on quantitative and qualitative characteristics of Maize (Zea mays L) under water deficit stress. Pakistan J. Biol. Sci. 10, 3585-3591. doi: 10.3923/pjbs.2007.3585.3591

EL Sabagh A, Hossain, A., Islam, M. S., Barutcular, C., Hussain, S., Hasanuzzaman, M., Akram, T., et al. (2019). Drought and salinity stresses in barley: consequences and mitigation strategies. Aust. J. Crop Sci. 13, 810-820. doi: 10.21475/ajcs.19.13.06.p1286

EL Sabagh A, Hossain, H., Islam, M. S., Barutcular, C., Ratnasekera, D., Gormus, O., Amanet, K., et al. (2020a). "Drought and heat stress in cotton (Gossypium hirsutum L.): consequences and their possible mitigation strategies," in Agronomic Crops, ed M. Hasanuzzaman (Singapore: Springer). p. 613-634. doi: 10.1007/978-981-15-0025-1_30

EL Sabagh, A., Hossain, A., Islam, M. S., Iqbal, M. A., Amanet, K., Mubeen, M., et al. (2021). "Prospective role of plant growth regulators for tolerance to abiotic stresses," in Plant Growth Regulators, eds T. Aftab and K. R. Hakeem (Cham: Springer), 1-38. doi: 10.1007/978-3-030-61153-8_1

EL Sabagh, A., Hossain, H., barutçular, C., Iqbal, M. A., Islam, M. S., Fahad, S., et al. (2020b). "Consequences of salinity stress on the quality of crops and its mitigation strategies for sustainable crop production: an outlook of arid and semi-arid regions," in Environment, Climate, Plant and Vegetation Growth, eds S. Fahad, M. Hasanuzzaman, M. Alam, H. Ullah, M. Saeed, I. A. Khan, and M. Adnan (Cham: Springer). p. 503-533. doi: 10.1007/978-3-030-49732-3_20
ElSayed, A. I., Boulila, M., Rafudeen, M. S., Mohamed, A. H., Sengupta, S., Rady, M., et al. (2020). Melatonin regulatory mechanisms and phylogenetic analyses of melatonin biosynthesis related genes extracted from peanut under salinity stress. Plants 9, 854. doi: 10.3390/plants 9070854

Fàbregas, N., Lozano-Elena, F., Blasco-Escámez, D., Tohge, T., MartínezAndújar, C., Albacete, A., et al. (2018). Overexpression of the vascular brassinosteroid receptor BRL3 confers drought resistance without penalizing plant growth. Nat. Commun. 9, 4680. doi: 10.1038/s41467-018-06 861-3

Fageria, N. K., Gheyi, H. R., and Moreira, A. (2011). Nutrient bioavailability in salt affected soils. J. Plant Nutr. 34, 945-962. doi: 10.1080/01904167.2011.555578

Fleet, C. M., and Sun, T. P. (2005). A DELLAcate balance: The role of gibberellin in plant morphogenesis. Curr. Opin. Plant Biol. 8, 77-85. doi: 10.1016/j.pbi.2004.11.015

Freitas, A. M., Nair, V. D., Harris, W. G., Mosquera-Losada, M. R., and Nair, P. K. R. (2017). Phosphorus Release Behavior of Biosolids and Corresponding Biochars in Abstract Retrieved From ASA, CSSA and SSSA International Annual Meetings. Available online at: https://scisoc.confex.com/ crops/2017am/webprogram/Paper106996.html (accessed August 20, 2021).

Gholami, M., Fakhari, A. R., and Ghanati, F. (2013). Selective regulation of nicotine and polyamines biosynthesis in tobacco cells by enantiomers of ornithine. Chirality 25, 22-27. doi: 10.1002/chir.22107

Gill, S. S., and Tuteja, N. (2010). Reactive oxygen species and antioxidant machinery in abiotic stress tolerance in crop plants. Plant Physiol. Biochem. 48, 909-930. doi: 10.1016/j.plaphy.2010.08.016

Gomez-Roldan, V., Fermas, S., Brewer, P. B., Puech-Pagès, V., Dun, E. A., Pillot, J. P., et al. (2008). Strigolactone inhibition of shoot branching. Nature 455, 189-194. doi: 10.1038/nature07271

Grove, M. D., Spencer, G. F., Rohwedder, W. K., Mandava, N., Worley, J. F., Warthen Jr, J. D., et al. (1979). Brassinolide, a plant growthpromoting steroid isolated from Brassica napus pollen. Nature 281, 216-217. doi: $10.1038 / 281216 \mathrm{a} 0$

Gujjar, R. S., Banyen, P., Chuekong, W., Worakan, P., Roytrakul, S., and Supaibulwatana, K. (2020). A synthetic cytokinin improves photosynthesis in rice under drought stress by modulating the abundance of proteins related to stomatal conductance, chlorophyll contents, and rubisco activity. Plants 9 , 1106. doi: 10.3390/plants9091106

Guo, D., Zhou, Y., Li, H. L., Zhu, J. H., Wang, Y., Chen, X. T., et al. (2017). Identification and characterization of the abscisic acid (ABA) receptor gene family and its expression in response to hormones in the rubber tree. Sci. Rep. 7, 45157. doi: 10.1038/srep45157

Gupta, S., Meena, M. K., and Datta, S. (2014). Isolation, characterization of plant growth promoting bacteria from the plant Chlorophytum borivilianum and invitro screening for activity of nitrogen fixation, phosphate solubilization and IAA production. Int. J. Curr. Microbiol. Appl. Sci. 3, 1082-1090.

Gururani, M. A., Venkatesh, J., and Tran, L.-S. (2015). Regulation of photosynthesis during abiotic stress-induced photoinhibition. Mol. Plant 8, 1304-1320. doi: 10.1016/j.molp.2015.05.005

Guschina, I. A., Harwood, J. L., Smith, M., and Beckett, R. P. (2002). Abscisic acid modifies the changes in lipid brought about by water stress in the moss (Atrichum androgynum). New Phytol. 156, 255-264. doi: 10.1046/j.1469-8137.2002.00517.x

Gyaneshwar, P., Parekh, L. J., Archana, G., Poole, P. S., Collins, M. D., Hutson, R. A., et al. (1999). Involvement of a phosphate-starvation inducible glucose dehydrogenase in soil phosphate solubilization by Enterobacter asburiae. FEMS Microbiol. Lett. 171, 223-229. doi: 10.1111/j.1574-6968.1999.tb1 3436.x

Ha, C. V., Leyva-Gonzalez, M. A., Osakabe, Y., Tran, U. T., Nishiyama, R., Watanabe, Y., et al. (2014). Positive regulatory role of strigolactone in plant responses to drought and salt stress. Proc. Natl. Acad. Sci. U.S.A. 111, 851-856. doi: 10.1073/pnas.1322135111

Hayward, A., Stirnberg, P., Beveridge, C., and Leyser, O. (2009). Interactions between auxin and strigolactone in shoot branching control. Plant Physiol. 151, 400-412. doi: 10.1104/pp.109.137646

He, M., He, C.-Q., and Ding, N.-Z. (2018). Abiotic stresses: general defenses of land plants and chances for engineering multistress tolerance. Front. Plant Sci. 9, 1771. doi: 10.3389/fpls.2018.01771 
Hedden, P., and Thomas, S. G. (2012). Gibberellin biosynthesis and its regulation. Biochem. J. 444, 11-25. doi: 10.1042/BJ20120245

Hong, Z., Ueguchi-Tanaka, M., Umemura, K., Uozu, S., Fujioka, S., Takatsuto, S., et al. (2003). A rice brassinosteroid-deficient mutant, ebisu dwarf (d2), is caused by a loss of function of a new member of cytochrome P450. Plant Cell 15, 2900-2910. doi: 10.1105/tpc.014712

Hoque, T., Hossain, M. A., Mostofa, M. G., Burritt, D., Fujita, M., and Tran, L.-S. (2016). Methylglyoxal: an emerging signaling molecule in plant abiotic stress responses and tolerance. Front. Plant Sci. 7, 1341. doi: 10.3389/fpls.2016.01341

Horváth, E., Pál, M., Szalai, G., Páldi, E., and Janda, T. (2007). Exogenous 4hydroxybenzoic acid and salicylic acid modulate the effect of short-term drought and freezing stress on wheat plants. Biol. Plantarum 51, 480-487. doi: 10.1007/s10535-007-0101-1

Hossain, A., Raza, A., and Maitra, S., Asaduzzaman Md et al. (2021). "Strigolactones: a novel carotenoid-derived phytohormone - biosynthesis, transporters, signalling, and mechanisms in abiotic stress," in Plant Growth Regulators, eds T. Aftab, and K. R. Hakeem (Cham: Springer), 275-303. doi: 10.1007/978-3-030-61153-8_13

Huang, J., Mishra, M., Palani, S., Chew, T. G., and Balasubramanian, M. K. (2016). Isolation of cytokinetic actomyosin rings from Saccharomyces cerevisiae and Schizosaccharomyces pombe. Methods Mol. Biol. 1369, 125-136. doi: 10.1007/978-1-4939-3145-3_10

Igarashi, K., and Kashiwagi, K. (2010). Modulation of cellular function by polyamines. Int. J. Biochem. Cell Biol. 42, 39-51. doi: 10.1016/j.biocel.2009.07.009

Iqbal, M., Basra, S. M. A., and Jamil, A. (2006). Seed enhancement with cytokinins: changes in growth and grain yield in salt stressed wheat plants. Plant Growth Regul. 50, 29-39. doi: 10.1007/s10725-006-9123-5

Iqbal, M. A. (2015a). Improving the growth and yield of canola (Brassica napus L.) with seed treatment and foliar sprays of brassica (Brassica naups L.) and moringa (Moringa oleifera L.) leaf extracts. Am. Eur. J. Agric. Environ. Sci. 14, 1067-1073. doi: 10.5829/idosi.aejaes.2014.14.10.12429

Iqbal, M. A. (2015b). Role of moringa, brassica and sorghum water extracts in increasing crops growth and yield: a review. Am. Eur. J. Agric. Environ. Sci. 14, 1150-1158. doi: 10.5829/idosi.aejaes.2014.14.11.12436

Islam, M. S., Hasan, M. K., Islam, B., Renu, N. A., Hakim, M. A., Islam, M. R., et al. (2021). Responses of water and pigments status, dry matter partitioning, seed production, and traits of yield and quality to foliar application of GA3 in mugnbean (Vigna radiata L.). Front. Agron. 2, 596850. doi: $10.3389 /$ fagro.2020.596850

Jain, M., and Khurana, J. P. (2009). Transcript profiling reveals diverse roles of auxin-responsive genes during reproductive development and abiotic stress in rice. FEBS J. 276, 3148-3162. doi: 10.1111/j.1742-4658.2009.07033.x

Javeed, H. M. R., Ali, M., Skalicky, M., Nawaz, F., Qamar, R., Rehman, A. U., et al. (2021). Lipoic acid combined with melatonin mitigates oxidative stress and promotes root formation and growth in salt-stressed canola seedlings (Brassica napus L.). Molecules. 26:3147. doi: 10.3390/molecules 26113147

Jha, Y., and Subramanian, R. B. (2013). Paddy plants inoculated with PGPR show better growth physiology and nutrient content under saline conditions. Chilean J. Agril. Res. 73, 2. doi: 10.4067/S0718-58392013000300002

Jurado, S., Abraham, Z., Manzano, C., López-Torrejón, G., Pacios, L. F., and Del Pozo, J. C. (2010). The Arabidopsis cell cycle F-box protein SKP2A binds to auxin. Plant Cell 22, 3891-3904. doi: 10.1105/tpc.110.078972

Kagale, S., Divi, U. K., Krochko, J. E., Keller, W. A., and Krishna, P. (2007). Brassinosteroid confers tolerance in Arabidopsis thaliana and Brassica napus to a range of abiotic stresses. Planta 225, 353-364. doi: 10.1007/s00425-006-0361-6

Kapulnik, Y., Resnick, N., Mayzlish-Gati, E., Kaplan, Y., Wininger, S., Hershenhorn, J., et al. (2011). Strigolactones interact with ethylene and auxin in regulating root-hair elongation in Arabidopsis. J. Exp. Bot. 62, 2915-2924. doi: $10.1093 / \mathrm{jxb} / \mathrm{erq} 464$

Kaur, H., Sirhindi, G., Bhardwaj, R., Alyemeni, M. N., Siddique, K. H. M., and Ahmad, P. (2018). 28-homobrassinolide regulates antioxidant enzyme activities and gene expression in response to salt and temperature-induced oxidative stress in Brassica juncea. Sci. Rep. 28, 8735. doi: 10.1038/s41598-018-27032-w

Kendrick, M. D., and Chang, C. (2008). Ethylene signaling: new levels of complexity and regulation. Curr. Opin. Plant Biol. 11, 479-485. doi: 10.1016/j.pbi.2008.06.011
Khan, R. U., Durrani, F. R., Chand, N., Anwar, H., Naz, S., Farooqi, F. A., et al. (2009). Effect of Cannabis sativa fortified feed on muscle growth and visceral organs in broiler chicks. Int. J. Biol. Biotech. 6, 179-182

Kloepper, J. W., Ryu, C. M., and Zhang, S. (2004). Induced systemic resistance and promotion of plant growth by Bacillus species. Phytopathology 94, 1259-1266. doi: 10.1094/PHYTO.2004.94.11.1259

Kohlen, W., Charnikhova, T., Liu, Q., Bours, R., Domagalska, M. A., Beguerie, S., et al. (2011). Strigolactones are transported through the xylem and play a key role in shoot architectural response to phosphate deficiency in nonarbuscular mycorrhizal host Arabidopsis. Plant Physiol. 155, 974-987. doi: 10.1104/pp.110.164640

Kovtun, Y. W., Chiu, W. L., Tena, G., and Sheen, J. (2000). Functional analysis of oxidative stress-activated mitogen-activated protein kinase cascade in plants. Proc. Natl. Acad. Sci. U.S.A. 97, 2940-2945. doi: 10.1073/pnas.97.6.2940

Lambers, H. (2003). Introduction, dry land salinity: a key environ. issue in Southern Australia. Plant Soil 257, 5-7. doi: 10.1023/B:PLSO.0000003909.80658.d8

Lee, S. B., and Suh, M. C. (2015). Advances in the understanding of cuticular waxes in Arabidopsis thaliana and crop species. Plant Cell Rep. 34, 557-572. doi: 10.1007/s00299-015-1772-2

Li, L., Xu, J., Xu, Z. H., and Xue, H. W. (2005). Brassinosteroids stimulate plant tropisms through modulation of polar auxin transport in Brassica and Arabidopsis. Plant Cell 17, 2738-2753. doi: 10.1105/tpc.105.034397

Ling, F., Su, Q., Jiang, H., et al. (2020). Effects of strigolactone on photosynthetic and physiological characteristics in salt-stressed rice seedlings. Sci. Rep. 10, 6183. doi: $10.1038 / \mathrm{s} 41598-020-63352-6$

Liu, H. Y., Yu, X., Cui, D. Y., Sun, M. H., Sun, W. N., et al. (2007). The role of water channel proteins and nitric oxide signaling in rice seed germination. Cell Res. 17, 638-649. doi: 10.1038/cr.2007.34

Liu, L., Nakamura, Y., Taliman, N. A., E. L., Sabagh, A., Moghaieb, R. E., et al. (2020). Differences in the growth and physiological responses of the leaves of Peucedanum japonicum and Hordeum vulgare exposed to salinity. Agriculture 10, 317. doi: 10.3390/agriculture10080317

Liu, Q., Yan, S., Huang, W., Yang, J.-Y., Dong, J., Zhang, S., et al. (2018). NAC transcription factor ONAC066 positively regulates disease resistance by suppressing the ABA signaling pathway in rice. Plant Mol. Biol. 98, 289-302. doi: $10.1007 / \mathrm{s} 11103-018-0768-\mathrm{z}$

Liu, Y., Huang, W., Xian, Z., Hu, N., Lin, D., Ren, H., Chen, J., and Su, D., Li Z (2017). Overexpression of SlGRAS40 in tomato enhances tolerance to abiotic stresses and influences auxin and gibberellin signaling. Front. Plant Sci. 8, 1659. doi: 10.3389/fpls.2017.01659

Llanes, A., Masciarelli, O., Ordoñez, R., Isla, M. I., and Luna, V. (2014). Differential growth responses to sodium salts involve different ABA catabolism and transport in the halophyte Prosopis strombulifera. Biol. Plant 58, 80-88. doi: 10.1007/s10535-013-0365-6

Lo, S. F., Ho, T. H. D., Liu, Y. L., Jiang, M. J., Hsieh, K. T., Chen, K. T., et al. (2017). Ectopic expression of specific GA 2 oxidase mutants promotes yield and stress tolerance in rice. Plant Biotechnol. J. 15, 850-864. doi: 10.1111/pbi.12681

Maheshwari, D. K., Dheeman, S., and Agarwal, M. (2015). "Phytohormoneproducing PGPR for sustainable agriculture," in Bacterial Metabolites in Sustainable Agroecosystem, ed D. K. Maheshwari (Cham: Springer), 159-182. doi: 10.1007/978-3-319-24654-3_7

Mahouachi, J., Arbona, V., and Gómez-Cadenas, A. (2007). Hormonal changes in papaya seedlings subjected to prograssive water stress in this halophyte. Plant Growth Regul. 53, 43-51. doi: 10.1007/s10725-007-9202-2

Mantelin, S., and Touraine, B. (2004). Plant growth-promoting bacteria and nitrate availability impacts on root development and nitrate uptake. J. Exp. Bot. 55, 27-34. doi: 10.1093/jxb/erh010

Marin, E., Jouannet, V., Herz, A., Lokerse, A. S., Weijers, D., Vaucheret, H., et al. (2010). miR390, arabidopsis TAS3 tasiRNAs, and their AUXIN RESPONSE FACTOR targets define an autoregulatory network quantitatively regulating lateral root growth. Plant Cell 22, 1104-1117. doi: 10.1105/tpc.109.072553

Mark, C., Zór, K., Heiskanen, A., Dufva, M., Emnéus, J., and Finnie, C. (2016). Monitoring intra-and extracellular redox capacity of intact barley aleurone layers responding to phytohormones. Anal. Biochem. 515, 1-8. doi: 10.1016/j.ab.2016.09.011

Martin, C. A., and Stutz, J. C. (2004). Interactive effects of temperature and arbuscular mycorrhizal fungi on growth, $\mathrm{P}$ uptake and root 
respiration of Capsicum annuum L. Mycorrhiza. 14, 241-244. doi: 10.1007/s00572-003-0261-6

Marzec, M. (2016). Perception and signaling of strigolactones. Front. Plant Sci. 7, 1260. doi: 10.3389/fpls.2016.01260

Marzec, M., Muszynska, A., and Gruszka, D. (2013). The role of strigolactones in nutrient-stress responses in plants. Int. J. Mol. Sci. 14, 9286-9304. doi: 10.3390/ijms14059286

Mayak, S., Tirosh, T., and Glick, B. R. (2004). Plant growth-promoting bacteria confer resistance in tomato plants to salt stress. Plant Physiol. Biochem. 42, 565-572. doi: 10.1016/j.plaphy.2004.05.009

Mellidou, I., Karamanoli, K., Beris, D., and Al, E. (2017). Underexpression of apoplastic polyamine oxidase improves thermotolerance in Nicotiana tabacum. J. Plant Physiol. 218, 171-174. doi: 10.1016/j.jplph.2017.08.006

Minocha, R., Majumdar, R., and Minocha, S. C. (2014). Polyamines and abiotic stress in plants: a complex relationship. Front. Plant Sci. 5, 175. doi: $10.3389 /$ fpls.2014.00175

Misra, N., and Saxena, P. (2009). Effect of salicylic acid on proline metabolism in lentil grown under salinity stress. Plant Sci. 177, 181-189. doi: 10.1016/j.plantsci.2009.05.007

Monsur, M. B., Ivy, N. A., Haque, M. M., Hasanuzzaman, M., E. L., and Sabagh, A., et al. (2020). Oxidative stress tolerance mechanism in rice under salinity. Phyton 89, 497-517. doi: 10.32604/phyton.2020.09144

Nadeem, S. M., Ahmad, M., Zahir, Z. A., Javaid, A., and Ashraf, M. (2014). The role of mycorrhizae and plant growth promoting rhizobacteria (PGPR) in improving crop productivity under stressful environments. Biotechnol. Adv. 32, 429-448. doi: 10.1016/j.biotechadv.2013.12.005

Nambara, E., and Marion-Poll, A. (2005). Abscisic acid biosynthesis and catabolism. Annu. Rev. Plant Biol. 56, 165-185. doi: 10.1146/annurev.arplant.56.032604.144046

Nolan, T., Chen, J., and Yin, Y. (2017). Cross-talk of brassinosteroid signaling in controlling growth and stress responses. Biochem. J. 474, 2641-2661. doi: 10.1042/BCJ20160633

Nolan, T., Vukasinovi, N., Liu, D., Russinova, E., and Yina, Y. (2020). Brassinosteroids: multidimensional regulators of plant growth, development, and stress responses. Plant Cell 32, 295-318. doi: 10.1105/tpc.19.00335

Ogweno, J. O., Song, X. S., Shi, K., et al. (2007). Brassinosteroids alleviate heatinduced inhibition of photosynthesis by increasing carboxylation efficiency and enhancing antioxidant systems in lycopersicon esculentum. J. Plant Growth Regul. 27, 49-57. doi: 10.1007/s00344-007-9030-7

Pál, M., Szalai, G., and Janda, T. (2015). Speculation: polyamines are important in abiotic stress signaling. Plant Sci. 237, 16-23. doi: $10.1016 /$ j.plantsci.2015.05.003

Pearce, S., Huttly, A. K., Prosser, I. M., Li, Y.-D., Vaughan, S. P., Gallova, B., et al. (2015). Heterologous expression and transcript analysis of gibberellin biosynthetic genes of grasses reveals novel functionality in the GA3ox family. BMC Plant Biol. 15, 130. doi: 10.1186/s12870-015-0520-7

Peleg, Z., and Blumwald, E. (2011). Hormone balance and abiotic stress tolerance in crop plants. Curr. Opin. Plant Biol. 14, 290-295. doi: 10.1016/j.pbi.2011.02.001

Pieterse, C. M. J., Leon-Reyes, A., Van Der Ent, S., and Van Wees, S. C. M. (2009). Networking by small-molecule hormones in plant immunity. Nat. Chem. Biol. 5, 308-316. doi: 10.1038/nchembio.164

Pishchik, V. N., Vorobyev, N. I., Chernyaeva, I. I., Timofeeva, S. V., Kozhemyakov, A. P., Alexeev, Y. V., et al. (2002). Experimental and mathematical simulation of plant growth promotingrhizobacteria and plant interaction under cadmium stress. Plant Soil 243, 173-186. doi: 10.1023/A:1019941525758

Pospíśilová J. (2003). Interaction of cytokinins and abscisic acid during regulation of stomatal opening in bean leaves. Photosynthetica 41, 49-56. doi: 10.1023/A:1025852210937

Potters, G., Pasternak, T. P., Guisez, Y., and Jansen, M. A. (2009). Different stresses, similar morphogenic responses: integrating a plethora of pathways. Plant Cell Environ. 32, 158-169. doi: 10.1111/j.1365-3040.2008.01908.x

Qi, Y. C., Wang, F. F., Zhang, H., and Liu, W. Q. (2010). Overexpression of suadea salsa S-adenosylmethionine synthetase gene promotes salt tolerance in transgenic tobacco. Acta Physiol. Plant 32, 263-269. doi: 10.1007/s11738-009-0403-3

Ralston, L., and Yu, O. (2006). Metabolons involving plant cytochrome P450s. Phytochem. Rev. 5, 459. doi: 10.1007/s11101-006-9014-4
Raza, M. A., van der Werf, W., and Ahmed M,Yang, W. (2020). Removing top leaves increases yield and nutrient uptake in maize plants. Nutr. Cycl. Agroecosyst. 118, 57-73. doi: 10.1007/s10705-020-10082-w

Reginato, M., Abdala, G. I., Miersch, O., Ruiz, O. A., Moschetti, E., and Luna, M. V. (2012). Changes in the levels of jasmonates and free polyamines induced by $\mathrm{Na}_{2} \mathrm{SO}_{4}$ and $\mathrm{NaCl}$ in roots and leaves of the halophyte Prosopis strombulifera. Biologia 67, 689-697. doi: 10.2478/s11756-012-0 052-7

Rivero, R. M., Gimeno, J., Van Deynze, A., Walia, H., and Blumwald, E. (2010). Enhanced cytokinin synthesis in tobacco plants expressing PSARK:IPT prevents the degradation of photosynthetic protein complexes during drought. Plant Cell Physiol. 51, 1929-1941. doi: 10.1093/pcp/pcq143

Rochange, S., Goormachtig, S., Lopez-Raez, J. A., and Gutjahr, C. (2019). "The role of strigolactones in plant-microbe interactions," in Strigolactones-Biology and Applications, eds H. Koltai and C. Prandi (Cham: Springer). p. 121-142. doi: 10.1007/978-3-030-12153-2_4

Russell, D. W., and Conn, E. (1967). The cinnamic acid 4hydroxylase of pea seedlings. Arch. Biochem. Biophys. 122, 256-258. doi: 10.1016/0003-9861(67)90150-6

Ruyter-Spira, C., Kohlen, W., Charnikhova, T., van Zeijl, A., van Bezouwen, L., de Ruijter, N., et al. (2011). Physiological effects of the synthetic strigolactone analog GR24 on root system architecture in Arabidopsis: another belowground role for strigolactones? Plant Physiol. 155, 721-734. doi: 10.1104/pp.110.166645

Sachs, T. (2005). Auxins role as an example of the mechanisms of shoot/root relations. Plant Soil 268, 13-19. doi: 10.1007/s11104-004-0173-z

Saini, S., Sharma, I., and Pati, P. K. (2015). Versatile roles of brassinosteroid in plants in the context of its homoeostasis, signaling and crosstalks. Front. Plant Sci. 6, 950. doi: 10.3389/fpls.2015.00950

Sakakibara, H. (2006). Cytokinins: Activity, biosynthesis, and translocation. Annu. Rev. Plant Biol. 57, 431-49. doi: 10.1146/annurev.arplant.57.032905.105231

Sakamoto, T., Morinaka, Y., Ohnishi, T., Sunohara, H., Fujioka, S., UeguchiTanaka, M., et al. (2006). Erect leaves caused by brassinosteroid deficiency increase biomass production and grain yield in rice. Nat. Biotechnol. 24, 105-109. doi: 10.1038/nbt1173

Sariyev, A., Barutcular, C., Acar, M., Hossain, A., E. L., and Sabagh, A. (2020). Sub-surface drip irrigation in associated with $\mathrm{H}_{2} \mathrm{O}_{2}$ improved the productivity of maize under clay-rich soil of Adana, Turkey. Phyton Int. J. Exp. Bot. 89, 519-528. doi: 10.32604/phyton.2020.09142

Sasaki-Sekimoto, Y., Taki, N., and Obayashi, T. (2005). Coordinated activation of metabolic pathways for antioxidants and defence compounds by jasmonates and their roles in stress tolerance in Arabidopsis. Plant J. 44, 653-668. doi: 10.1111/j.1365-313X.2005.02560.x

Seiler, N., and Raul, F. (2005). Polyamines and apoptosis. J. Cell. Mol. Med. 9, 623-642. doi: 10.1111/j.1582-4934.2005.tb00493.x

Serna, M., Coll, Y., Zapata, P. J., Botella, M. A., Pretel, M. T., and Amorós, A. (2015). A brassinosteroid analogue prevented the effect of salt stress on ethylene synthesis and polyamines in lettuce plants. Sci. Hort. 185, 105-112. doi: 10.1016/j.scienta.2015.01.005

Shaharoona, B., Naveed, M., Arshad, M., and Zahir, Z. A. (2008). Fertilizerdependent efficiency of pseudomonads for improving growth, yield, and nutrient use efficiency of wheat (Triticum aestivum L). Appl. Microbiol. Biotechnol. 79, 147-155. doi: 10.1007/s00253-008-1419-0

Sharif, R., Xie, C., Zhang, H., Arnao, M. B., Ali, M., Ali, Q., et al. (2018). Melatonin and its effects on plant systems. Molecules 23, 2352. doi: 10.3390/molecules23092352

Shi, Y., Tian, S., Hou, L., Huang, X., Zhang, X., Guo, H., et al. (2012). Ethylene signaling negatively regulates freezing tolerance by repressing expression of CBF and type-A ARR genes in Arabidopsis. Plant Cell 24, 2578-2595. doi: $10.1105 /$ tpc. 112.098640

Silverman, P., Seskar, M., Kanter, D., Schweizer, P., Metraux, J. P., and Raskin, I. (1995). Salicylic acid in rice. Plant Physiol. 108, 633-639. doi: $10.1104 /$ pp.108.2.633

Singhal, R. K., Saha, D., Skalicky, M., Mishra, U. N., Chauhan, J., Behera, L. P., et al. (2021). Crucial cell signaling compounds crosstalk and integrative multi-omics techniques for salinity stress tolerance in plants. Front. Plant Sci. 12, 670369. doi: 10.3389/fpls.2021.670369

Slama, I., Abdelly, C., Bouchereau, A., Flower, T., and Savour,é A. (2015). Diversity, distribution and roles of osmoprotective compounds 
accumulated in halophytes under abiotic stress. Ann. Bot. 115, 433-447. doi: 10.1093/aob/mcu239

Su, Y.i, Xia, S., Wang, R., and Xiao, L. (2017). Phytohormonal quantification based on biological principles. Hormone Metabol. Signal. Plants 2017, 431-470. doi: 10.1016/B978-0-12-811562-6.00013-X

Sun, Q., Zhang, N., Wang, J., Zhang, H., Li, D., Shi, J., et al. (2014). Melatonin promotes ripening and improves quality of tomato fruit during postharvest life. J. Exp. Bot. 66, 657-668. doi: 10.1093/jxb/eru332

Symons, G. M., Ross, J. J., Jager, C. E., and Reid, J. B. (2008). Brassinosteroid transport. J. Exp. Bot. 59, 17-24. doi: 10.1093/jxb/erm098

Taiz, L., Zeiger, E., Møller, I. M., and Murphy, A. (2015). Plant Physiology and Development, Sixth Edition. Massachusetts: Sinauer Associates, Inc.

Takahashi, Y., Tahara, M., Yamada, Y., and Al, E. (2017). Characterization of the polyamine biosynthetic pathways and salt stress response in Brachypodium distachyon. J. Plant Growth Regul. 37, 625-634. doi: 10.1007/s00344-017-9761-Z

Takeuchi, K., Gyohda, A., Tominaga, M., Kawakatsu, M., Hatakeyama, A., Ishii, N., et al. (2011). RSOsPR10 expression in response to environmental stresses is regulated antagonistically by jasmonate/ethylene and salicylic acid signaling pathways in rice roots. Plant Cell Physiol. 52, 1686-1696. doi: $10.1093 / \mathrm{pcp} / \mathrm{pcr} 105$

Terré S., Asch, F., Padham, J., Sikora, R. A., and Becker, M. (2007). "Influence of root zone bacteria on root iron plaque formation in rice subjected to iron toxicity," in Utilisation of Diversity in Land Use Systems: Sustainable and Organic Approaches to Meet Human Needs, ed E. Tielkes (Witzenhausen: Tropentag), 446.

Tognetti, V. B., Müllenbock, P. E. R., and Van Breusegem, F. (2012). Stress homeostasis-the redox and auxin perspective. Plant Cell Environ. 35, 321-333. doi: 10.1111/j.1365-3040.2011.02324.x

Tromas, A., Braun, N., Muller, P., et al. (2009). The auxin binding protein 1 is required for differential auxin responses mediating root growth. PLoS ONE 4, e6648. doi: 10.1371/journal.pone.0006648

Turan, M., Gulluce, M., von Wirén, N., and Sahin, F. (2012). Yield promotion and phosphorus solubilization by plant growth-promoting rhizobacteria in extensive wheat production in Turkey. J. Plant Nutr. Soil Sci. 175, 818-826. doi: 10.1002/jpln.201200054

Umehara, M., Hanada, A., Yoshida, S., Akiyama, K., Arite, T., Takeda-Kamiya, N., et al. (2008). Inhibition of shoot branching by new terpenoid plant hormones. Nature 455, 195-200. doi: 10.1038/nature07272

Vessey, J. K. (2003). Plant growth promoting rhizobacteria as biofertilizers. Plant Soil 255, 571-586. doi: 10.1023/A:1026037216893

Viveros, O. M., Jorquera, M. A., Crowley, D. E., Gajardo, G., and Mora, M. L. (2010). Mechanisms and practical considerations involved in plant growth promotion by rhizobacteria. J. Soil Sci. Plant Nutr. 10, 293-319. doi: 10.4067/S0718-95162010000100006

Vriet, C., Russinova, E., and Reuzeau, C. (2013). From squalene to brassinolide: the steroid metabolic and signaling pathways across the plant kingdom. Mol. Plant 6, 1738-1757. doi: 10.1093/mp/sst096

Vukašinović N., and Russinova, E. (2018). BRexit: Possible brassinosteroid export and transport routes. Trends Plant Sci. 23, 285-292. doi: 10.1016/j.tplants.2018.01.005

Wang, Y., Reiter, R. J., and Chan, Z. (2017). Phytomelatonin: a universal abiotic stress regulator. J. Exp. Bot. 69, 963-974. doi: 10.1093/jxb/erx473

Wasternack, C. (2007). Jasmonates: An Update on Biosynthesis, Signal Transduction and Action in Plant Stress Response, Growth and Development. Ann. Bot. 100, 681-697. doi: 10.1093/aob/mcm079

Wasternack, C. (2014). Action of jasmonates in plant stress responses and development-applied aspects. Biotechnol. Adv. 32, 31-39. doi: 10.1016/j.biotechadv.2013.09.009

Wasternack, C., and Hause, B. (2013). Jasmonates: biosynthesis, perception, signal transduction and action in plant stress response, growth and development. An update to the 2007 review in Annals of Botany. Ann. Bot. 111, 1021-1058. doi: $10.1093 / \mathrm{aob} / \mathrm{mct} 067$

Williams, M. E. (2011). Introduction to phytohormones. Teaching tools in plant biology: lecture notes. Plant Cell. 22:1. doi: 10.1105/tpc.118.tt0718

Wilmoth, J. C., Wang, S., Tiwari, S. B., Joshi, A. D., Hagen, G., Guilfoyle, T. J., et al. (2005). NPH4/ARF7 and ARF19 promote leaf expansion and auxin-induced lateral root formation. Plant J. 43, 118-130. doi: 10.1111/j.1365-313X.2005.02432.x
Woodward, A. W., and Bartel, B. (2005). Auxin: regulation and interaction. Ann. Bot. 95, 707-735. doi: 10.1093/aob/mci083

$\mathrm{Xu}, \mathrm{C}$., Wu, X., and Zhang, H. (2009). Impact of D-Arg on drought resistance and endogenous polyamines in mycorrhizal Pinus massoniana. J. Nanjing Forestry Univ. 33, 19-23.

Xu, Z.-Y., Kim, S. Y., Hyeon, D. Y., Kim, D. H., Dong, T., Park, Y., et al. (2013). The arabidopsis NAC transcription factor ANAC096 cooperates with bZIP-type transcription factors in dehydration and osmotic stress responses. Plant Cell 25, 4708-4724. doi: 10.1105/tpc.113.119099

Yadav, B., Jogawat, A., Gnanasekaran, P., Kumari, P., Lakra, N., Lal, S. K., et al. (2021). An overview of recent advancement in phytohormones-mediated stress management and drought tolerance in crop plants. Plant Gene 25, 100264. doi: $10.1016 /$ j.plgene.2020.100264

Yalpani, N., Shulaev, V., and Raskin, I. (1993). Endogenous salicylic acid levels correlate with accumulation of Pathogenesis-Related proteins and virus resistance in tobacco. Phytopathology 83, 702-708. doi: 10.1094/Phyto-83-702

Yamaguchi, S. (2008). Gibberellin metabolism and its regulation. Ann. Rev. Plant Biol. 59, 225-251. doi: 10.1146/annurev.arplant.59.032607.092804

Yamamuro, C., Ihara, Y., Wu, X., Noguchi, T., Fujioka, S., Takatsuto, S., et al. (2000). Loss of function of a rice brassinosteroid insensitive1 homolog prevents internode elongation and bending of the lamina joint. Plant Cell 12, 1591-1606. doi: 10.1105/tpc.12.9.1591

Yang, C., Li, W., Cao, J., Meng, F., Yu, Y., Huang, J., et al. (2017). Activation of ethylene signaling pathways enhances disease resistance by regulating ROS and phytoalexin production in rice. Plant J. 89, 338-3531. doi: 10.1111/tpj.13388

Yang, J., Thames, S., Best, N. B., Jiang, H., Huang, P., Dilkes, B. P., and Eveland, A. L. (2018). Brassinosteroids modulate meristem fate and differentiation of unique inflorescence morphology in Setaria viridis. Plant Cell. 30, 48-66. doi: 10.1105/tpc.17.00816

Yin, Y., Jiang, X., Ren, M., Xue, M., Nan, D., Wang, Z., et al. (2018). AmDREB2C, from Ammopiptanthus mongolicus, enhances abiotic stress tolerance and regulates fatty acid composition in transgenic Arabidopsis. Plant Physiol. Biochem. 130, 517-528. doi: 10.1016/j.plaphy.2018.08.002

Yoshikawa, H., Honda, C., and Kondo, S. (2007). Effect of low-temperature stress on abscisic acid, jasmonates, and polyamines in apples. Plant Growth Regul. 52, 199-206. doi: 10.1007/s10725-007-9190-2

Yuan, G. F., Jia, C. G., Li, Z., Sun, B., Zhang, L. P., Liu, N., et al. (2010). Effect of brassinosteroids on drought resistance and abscisic acid concentration in tomato under ater stress. Sci. Hortic. 126, 103-108. doi: 10.1016/j.scienta.2010.06.014

Zhang, X., and Chang, X. (2016). "Conclusion," in The Logic of Economic Reform in China. China Insights, eds X. Zhang and X. Chang (Berlin; Heidelberg: Springer), 197-200. doi: 10.1007/978-3-662-47404-4_11

Zhao, M., Liu, W., Xia, X., Wang, T., and Zhang, W. H. (2014). Cold acclimationinduced freezing tolerance of Medicago truncatula seedlings is negatively regulated by ethylene. Physiol. Plantarum 152, 115-129. doi: 10.1111/ppl.12161

Conflict of Interest: The authors declare that the research was conducted in the absence of any commercial or financial relationships that could be construed as a potential conflict of interest.

Publisher's Note: All claims expressed in this article are solely those of the authors and do not necessarily represent those of their affiliated organizations, or those of the publisher, the editors and the reviewers. Any product that may be evaluated in this article, or claim that may be made by its manufacturer, is not guaranteed or endorsed by the publisher.

Copyright (C) 2022 EL Sabagh, Islam, Hossain, Iqbal, Mubeen, Waleed, Reginato, Battaglia, Ahmed, Rehman, Arif, Athar, Ratnasekera, Danish, Raza, Rajendran, Mushtaq, Skalicky, Brestic, Soufan, Fahad, Pandey, Kamran, Datta and Abdelhamid. This is an open-access article distributed under the terms of the Creative Commons Attribution License (CC BY). The use, distribution or reproduction in other forums is permitted, provided the original author(s) and the copyright owner(s) are credited and that the original publication in this journal is cited, in accordance with accepted academic practice. No use, distribution or reproduction is permitted which does not comply with these terms. 